\title{
Mitochondrial Succinate Metabolism and Reactive Oxygen Species Are Important but Not Essential for Eliciting Carotid Body and Ventilatory Responses to Hypoxia in the Rat
}

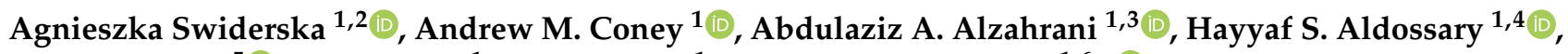 \\ Nikolaos Batis ${ }^{5}{ }^{\oplus}$, Clare J. Ray ${ }^{1}$, Prem Kumar ${ }^{1}$ and Andrew P. Holmes ${ }^{1,6, *(\mathbb{C}}$
}

1 Institute of Clinical Sciences, University of Birmingham, Edgbaston, Birmingham B15 2TT, UK; agnieszka.swiderska@postgrad.manchester.ac.uk (A.S.); a.m.coney@bham.ac.uk (A.M.C.); AAA717@student.bham.ac.uk (A.A.A.); HXA807@student.bham.ac.uk (H.S.A.); c.j.ray@bham.ac.uk (C.J.R.); p.kumar@bham.ac.uk (P.K.)

2 Manchester Academic Health Sciences Centre, Unit of Cardiac Physiology, 3.26 Core Technology Facility, Institute of Cardiovascular Sciences, The University of Manchester, 46 Grafton Street, Manchester M13 9NT, UK

3 Respiratory Care Department, Faculty of Applied Medical Sciences, Umm Al-Qura University, Makkah 24381, Saudi Arabia

4 Basic Medical Sciences, College of Medicine, King Saud bin Abdulaziz University for Health Sciences, Riyadh 11481, Saudi Arabia

check for updates

Citation: Swiderska, A.; Coney, A.M.; Alzahrani, A.A.; Aldossary, H.S.; Batis, N.; Ray, C.J.; Kumar, P.; Holmes, A.P. Mitochondrial Succinate Metabolism and Reactive Oxygen Species Are Important but Not Essential for Eliciting Carotid Body and Ventilatory Responses to Hypoxia in the Rat. Antioxidants 2021, 10, 840. https://doi.org/10.3390/ antiox10060840

Academic Editors: Asuncion Rocher and Philip I. Aaronson

Received: 13 April 2021

Accepted: 21 May 2021

Published: 25 May 2021

Publisher's Note: MDPI stays neutral with regard to jurisdictional claims in published maps and institutional affiliations.

Copyright: (c) 2021 by the authors. Licensee MDPI, Basel, Switzerland. This article is an open access article distributed under the terms and conditions of the Creative Commons Attribution (CC BY) license (https:/ / creativecommons.org/licenses/by/ $4.0 /)$.
5 Institute of Cancer and Genomic Sciences, University of Birmingham, Edgbaston, Birmingham B15 2TT, UK; N.Batis@bham.ac.uk

6 Institute of Cardiovascular Sciences, University of Birmingham, Edgbaston, Birmingham B15 2TT, UK

* Correspondence: a.p.holmes@bham.ac.uk; Tel.: +44-121-415-8161

Abstract: Reflex increases in breathing in response to acute hypoxia are dependent on activation of the carotid body (CB)-A specialised peripheral chemoreceptor. Central to $\mathrm{CB} \mathrm{O}_{2}$-sensing is their unique mitochondria but the link between mitochondrial inhibition and cellular stimulation is unresolved. The objective of this study was to evaluate if ex vivo intact CB nerve activity and in vivo whole body ventilatory responses to hypoxia were modified by alterations in succinate metabolism and mitochondrial ROS (mitoROS) generation in the rat. Application of diethyl succinate (DESucc) caused concentration-dependent increases in chemoafferent frequency measuring approximately $10-30 \%$ of that induced by severe hypoxia. Inhibition of mitochondrial succinate metabolism by dimethyl malonate (DMM) evoked basal excitation and attenuated the rise in chemoafferent activity in hypoxia. However, approximately $50 \%$ of the response to hypoxia was preserved. MitoTEMPO (MitoT) and 10-(6'-plastoquinonyl) decyltriphenylphosphonium (SKQ1) (mitochondrial antioxidants) decreased chemoafferent activity in hypoxia by approximately $20-50 \%$. In awake animals, MitoT and SKQ1 attenuated the rise in respiratory frequency during hypoxia, and SKQ1 also significantly blunted the overall hypoxic ventilatory response (HVR) by approximately $20 \%$. Thus, whilst the data support a role for succinate and mitoROS in $\mathrm{CB}$ and whole body $\mathrm{O}_{2}$-sensing in the rat, they are not the sole mediators. Treatment of the $\mathrm{CB}$ with mitochondrial selective antioxidants may offer a new approach for treating CB-related cardiovascular-respiratory disorders.

Keywords: carotid body; hypoxia; succinate; mitochondrial reactive oxygen species; succinate dehydrogenase; hypoxic ventilatory response

\section{Introduction}

The ability for humans to sense and respond to a fall in blood oxygen (hypoxia/hypoxaemia) has never been so apparent as in the current COVID-19 pandemic, in which millions of people have experienced this life-threatening stressor [1]. When challenged by hypoxia, the carotid body $(\mathrm{CB})$ is the major peripheral chemoreceptor that detects this stimulus within seconds [2,3]. In contrast to almost all other cell types, the CB type I 
cell has an extraordinarily high sensitivity to $\mathrm{O}_{2}$, with its activity increasing exponentially from mild levels of hypoxia [4]. Upon stimulation, the CB activates numerous critical protective reflexes including hyperventilation, tachycardia, systemic vasoconstriction, and adrenaline release $[5,6]$. These reflexes are essential to preserve enough $\mathrm{O}_{2}$ delivery to the brain and vital organs, helping to support survival.

What remains controversial is the precise mechanism by which the CB senses hypoxia, with many different mechanisms being proposed [7]. One of the most longstanding hypotheses is that during hypoxia, CB mitochondrial electron transport is inhibited [8,9]. Importantly, the CBs express unique mitochondria which have a much lower $\mathrm{O}_{2}$ affinity in contrast with other cell types [8-11]. Functional experiments have shown that mitochondrial inhibition in CB type I cells starts to occur as the $\mathrm{PO}_{2}$ falls below a threshold of between $40-60 \mathrm{mmHg}$, i.e., considerably above the normal value of less than $5 \mathrm{mmHg}$ observed in other cells [9]. As such, CB mitochondrial inhibition, activation of the chemotransduction cascade, and initiation of protective reflexes can be achieved in response to relatively small falls in blood $\mathrm{PO}_{2}$ from normoxic values and before the metabolism or function of other cells starts to be impaired [11].

A key consideration is the link between mitochondrial inhibition and activation of the downstream chemotransduction cascade [11,12]. Suggested mechanisms include a rise in [lactate $]_{i}[13]$, a fall in $[\mathrm{MgATP}]_{i}[14,15]$, and/or stimulation of AMP-activated protein kinase (AMPK) [16]. A recent hypothesis is that during hypoxia, an elevation in mitochondrial reactive oxygen species (mitoROS) generation at complex I is sufficient to cause membrane $\mathrm{K}^{+}$channel closure and chemostimulation $[17,18]$. Mice lacking the complex I $n d u f s 2$ gene do not display an increase in respiratory frequency when subjected to hypoxia [17]. CB type I cells isolated from $n d u f s 2$ deficient mice do not exhibit rises in either mitoROS or intracellular $\mathrm{Ca}^{2+}$ in response to hypoxia $[17,18]$. Importantly, the elevation in mitoROS is proposed to be dependent on a rise in succinate metabolism at complex II, reverse electron transport (RET), and the oxidation of ubiquinol $\left(\mathrm{QH}_{2}\right)$ to ubiquinone (Q) at complex I [18,19]. It is currently unclear if selective pharmacological targeting of mitochondria with antioxidants can abolish or dampen the CB chemoafferent or whole animal response to hypoxia. Information of this type should underpin development of treatments for CB hyperactivity, an emerging driver of neurogenic hypertension $[20,21]$.

Countering the idea that complex I-derived mitoROS are essential for $\mathrm{CB} \mathrm{O}_{2}$ sensing is the finding that type I cell hypoxic sensitivity can be retained in the presence of rotenone (complex I inhibitor) by feeding electrons directly to cytochrome c [22]. Furthermore, CB type I cells isolated from mice with heterozygous deletion of the mitochondrial complex II gene SDHD (encoding succinate dehydrogenase (SDH) subunit D) display the same neurosecretory response to hypoxia as those obtained from wildtype littermates, raising questions about the importance of succinate in hypoxic chemotransduction [23]. No study has directly examined the role of succinate metabolism and mitoROS generation in mediating $\mathrm{CB}$ or ventilatory $\mathrm{O}_{2}$ sensitivity in the rat.

The aim of the current study was to evaluate if ex vivo CB chemoafferent activity and in vivo ventilatory responses to hypoxia could be modified by alterations in succinate metabolism and mitoROS signalling in the rat.

\section{Materials and Methods}

\subsection{Ethical Approval}

All procedures were performed in accordance with UK Animals (Scientific Procedures) Act 1986 and approved by the UK Home Office (PPL number PF4C074AD) and by the Animal Welfare and Ethical Review Body (AWERB) at the University of Birmingham. Adult male Wistar rats ( $n=98,5-10$ weeks, $120-390 \mathrm{~g})$ were purchased from Charles River, UK. Animals were housed in individually ventilated cages $(n=2-4$ per cage) under standard conditions: 12:12 h light:dark cycle (lights on at 0700), $22{ }^{\circ} \mathrm{C}$ and $55 \%$ humidity. Food and water were available ad libitum. Animals were killed humanely by either exposure 
to carbon dioxide gas in a rising concentration or by dislocation of the neck (following removal of CBs under terminal non recovery anaesthesia).

\subsection{Recordings of $C B$ Chemoafferent Nerve Activity}

CBs were isolated from adult male Wistar rats under deep non-recovery terminal inhalation anaesthesia (3-5\% isoflurane in $\mathrm{O}_{2}, 1.5 \mathrm{~L} \mathrm{~min}^{-1}$ ) as previously described [24,25]. Depth of anaesthesia was monitored during the procedure by absence of a hind limb flexor withdrawal reflex and breathing frequency.

Intact carotid bifurcations containing the carotid sinus nerve (CSN) and CB were removed and animals immediately killed by cervical dislocation. The tissue was transferred to a recording chamber (volume of approximately $0.2 \mathrm{~mL}$ ) with a Sylgard 184 base (Dow Corning, Midland, MI, USA) and continuously superfused with a bicarbonate buffered Krebs solution containing, in mM: $119 \mathrm{NaCl}, 4.5 \mathrm{KCl}, 1.2 \mathrm{NaH}_{2} \mathrm{PO}_{4}, 1.2 \mathrm{MgSO}_{4} .7 \mathrm{H}_{2} \mathrm{O}$, $25 \mathrm{NaHCO}_{3}, 2.4 \mathrm{CaCl}_{2}$, and $11 \mathrm{D}$-glucose, $37{ }^{\circ} \mathrm{C}$, pH 7.4, equilibrated with $95 \% \mathrm{O}_{2}, 5 \%$ $\mathrm{CO}_{2}$. The CSN was identified, dissected-free and surrounding connective tissue removed. To aid with extracellular recording [26,27], the tissue was partially digested in a Krebs solution containing $0.075 \mathrm{mg} \mathrm{mL}^{-1}$ collagenase type II and $0.0025 \mathrm{mg} \mathrm{mL}^{-1}$ dispase type I (Sigma-Aldrich, Gillingham, UK), for 20-30 min.

Extracellular action potential recordings of single and few-fibre units were recorded from the cut end of the CSN using borosilicate glass pipettes as described [28,29]. Acquisition and analysis were performed using Spike2 (version 7.12) software (Cambridge Electronic Design, Cambridge, UK). Raw chemoafferent voltage was amplified x5000 and sampled at $15 \mathrm{kHz}$. Single units were used for frequency analysis. These were discriminated initially by thresholding and subsequently by comparison of specific AP waveform parameters such as amplitude, $50 \%$ repolarisation time, and time to peak hyperpolarisation.

Experiments were performed at $37^{\circ} \mathrm{C}$ and superfusate $\mathrm{PO}_{2}$ was continuously measured $(100 \mathrm{~Hz})$ using an $\mathrm{O}_{2}$ electrode $\left(\mathrm{ISO}_{2}\right)$ and $\mathrm{O}_{2}$ meter (OXELP; World Precision Instruments, Hitchin, UK). Basal activity was measured at ca. $300 \mathrm{mmHg}$ and hypoxic responses were induced by a slow ramp down to ca. $100 \mathrm{mmHg}$ before rapid reversal into hyperoxia $\left(95 \% \mathrm{O}_{2}, 5 \% \mathrm{CO}_{2}\right)$. Single fibre frequency was plotted against the superfusate $\mathrm{PO}_{2}$ and data fitted to an exponential curve with offset:

$$
y=a+b \times \operatorname{Exp}\left({ }^{-c x}\right)
$$

where $y$ is the discharge frequency $(\mathrm{Hz}), x$ is the superfusate $\mathrm{PO}_{2}(\mathrm{mmHg}), a$ is the discharge frequency as the $\mathrm{PO}_{2}$ tends to infinity (offset), $b$ is the theoretical frequency when the $\mathrm{PO}_{2}$ is $0 \mathrm{mmHg}$ (minus the offset), and $c$ is the exponential rate constant.

Hypoxic responses were performed under control conditions and in the presence of pharmacological agents at concentrations consistent with those shown to modify mitochondrial succinate metabolism and mitoROS generation. These included diethyl Succinate [30] (DESucc, 1 and $5 \mathrm{mM}$, Sigma-Aldrich, Gillingham, UK), dimethyl malonate [19,30] (DMM, mitochondrial complex II inhibitor, Sigma-Aldrich, Gillingham, UK), MitoTEMPO [30,31] (20 $\mu \mathrm{M}$, MitoT, mitochondrial antioxidant, targeted to the matrix, Sigma-Aldrich, Gillingham, UK), and 10-(6'-plastoquinonyl) decyltriphenylphosphonium [32,33] (1 $\mu \mathrm{M}, \mathrm{SKQ} 1$, mitochondrial antioxidant targeted to the intermembrane space, Bio-Techne Ltd., Abingdon, UK). Incubation time was $5 \mathrm{~min}$ for DESucc and DMM and 20-25 min for MitoT and SKQ1 to allow for sufficient uptake.

\subsection{Ventilatory Responses to Hypoxia and Hypercapnia}

Respiratory parameters in unrestrained awake animals were recorded using whole body plethysmography (WBP) specifically designed for rats as described [34]. Gas flow into the chamber was approximately $2 \mathrm{~L} \mathrm{~min}^{-1}$. The WBP chamber was perfused with either a normoxic $\left(78.97 \% \mathrm{~N}_{2}, 21 \% \mathrm{O}_{2}, 0.03 \% \mathrm{CO}_{2}\right)$, hypoxic $\left(89.97 \% \mathrm{~N}_{2}, 10 \% \mathrm{O}_{2}, 0.03 \% \mathrm{CO}_{2}\right)$, or hypercapnic $\left(73 \% \mathrm{~N}_{2}, 21 \% \mathrm{O}_{2}, 6 \% \mathrm{CO}_{2}\right)$ gas mixture, controlled using Iox2.9.11.8 software (EMKA Technologies, Paris, France). Respiratory flow data were sampled at 
$1000 \mathrm{~Hz}$ and respiratory frequency $\left(\mathrm{R}_{\mathrm{f}}\right)$, tidal volume $\left(\mathrm{V}_{\mathrm{T}}\right)$, and minute ventilation $\left(\mathrm{V}_{\mathrm{E}}\right)$ were calculated offline.

WBP was performed between 8:30 a.m. to 14:00 p.m. Rats were individually placed in the WBP chamber and allowed to acclimatise for 15-30 min. Following acclimatisation, a 5-min baseline was recorded. Rats were then exposed to a cycle of hypoxia (10\% $\left.\mathrm{O}_{2}, 5 \mathrm{~min}\right) /$ normoxia (5 min) and immediately after to a cycle of hypercapnia $\left(6 \% \mathrm{CO}_{2}\right.$, $5 \mathrm{~min}$ )/normoxia (10 $\mathrm{min})$. The final $2 \mathrm{~min}$ of hypoxic/hypercapnic exposure was used for analysis. Rats were removed from the WBP chamber and received an intraperitoneal (I.P.) injection of either vehicle or mitochondrial antioxidant (MitoT-1.96 $\mu \mathrm{M} \mathrm{kg}^{-1} / 19.6 \mu \mathrm{M} \mathrm{kg}^{-1}$, SKQ1 $500 \mathrm{nM} \mathrm{kg}^{-1}$ ). All solutions were prepared fresh on the day of experimentation and injection volume did not exceed $1 \mathrm{~mL} \mathrm{~kg}^{-1}$ bodymass. After one hour in the home cage, rats were placed back into the WBP chamber and the respiratory protocol was repeated.

\subsection{Data Analysis}

Data are presented as mean \pm SEM or as box-whisker plots with median, mean (shown as + ), the box representing the interquartile range and the whiskers extending to outliers. Single points represent individual chemoafferent fibres or animals. Statistical analysis was performed using (i) a paired 2-tailed student's $t$-test, (ii) repeated measures one-way analysis of variance (ANOVA) or (iii) repeated measures two-way ANOVA with Tukey or Dunnett's post hoc analysis where appropriate (Prism v9, GraphPad Software, San Diego, CA, USA). Significance was taken as $p<0.05$.

\section{Results}

\subsection{Succinate Causes Significant CB Chemoafferent Excitation}

Application of the cell permeable compound diethyl succinate (DESucc; $1-10 \mathrm{mM}$ ) increased chemoafferent activity in a concentration dependent manner (Figure 1a,b). The onset of the response was quick, achieving steady state within $3 \mathrm{~min}$, and was rapidly reversible (Figure 1a). At the highest concentration $(10 \mathrm{mM})$, the frequency peaked within the range of 1.5-5 Hz (Figure 1b). In four experiments, application of $20 \mathrm{mM}$ DESucc was tested but we did not observe any further rise in frequency, measuring $1.9 \pm 0.7 \mathrm{~Hz}$, $n=4$. Prolonged exposure of the CB to $5 \mathrm{mM}$ DESucc demonstrated that the chemoafferent frequency did not continue to rise, but rather peaked at $5 \mathrm{~min}$, remained elevated at 15 min before returning to, or slightly below baseline (Figure 1c). Even at the highest concentrations, the response to DESucc was relatively modest compared to hypoxia (Figure 2a). Experiments performed on the same $C B$ preparations showed that the maximum rise in chemoafferent frequency induced by DESucc was approximately $10-30 \%$ of that induced by a subsequent severe hypoxic stimulus (Figure 2a,b). Thus, although excessive succinate metabolism did cause CB stimulation, it did not precisely mimic hypoxia. Chemoafferent excitation induced by $5 \mathrm{mM}$ DESucc was almost completely abolished by $10 \mathrm{mM}$ DMM, a competitive inhibitor of mitochondrial complex II (Figure 2c,d). Furthermore, excitation caused by DESucc was attenuated in the presence of two different mitochondrial antioxidants MitoT (targeted to the mitochondrial matrix; $20 \mu \mathrm{M}$ ) and SKQ1 (targeted to the mitochondrial intermembrane space; $1 \mu \mathrm{M}$ ) (Figure 2e-h). 
(a)

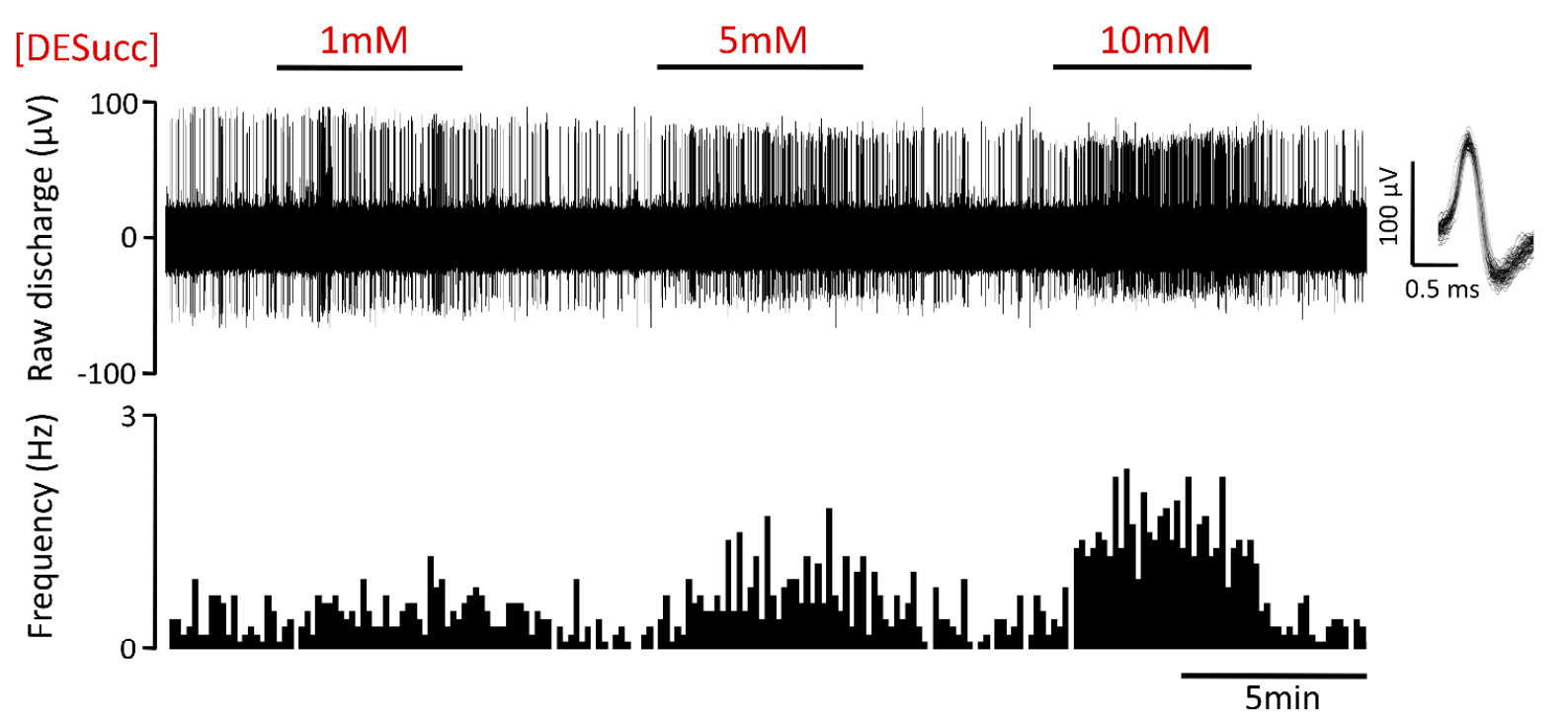

(b)

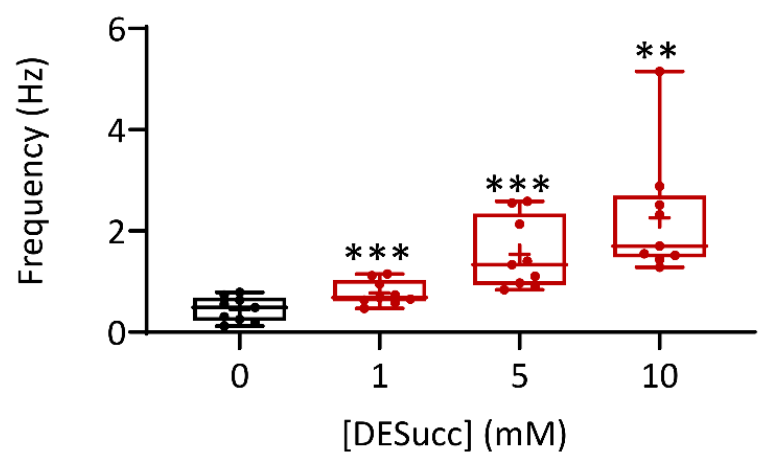

(c)

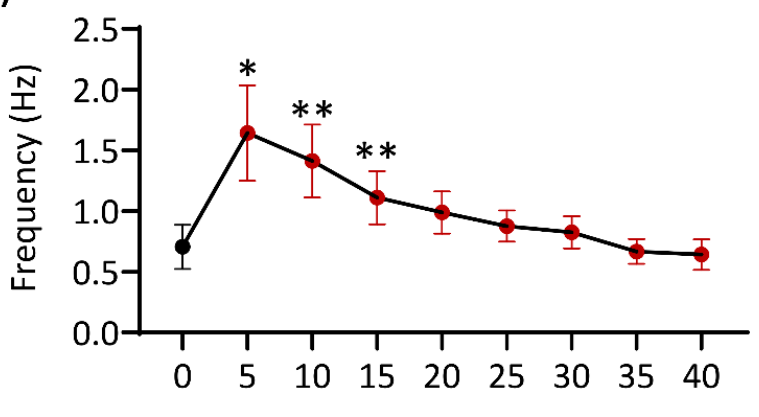

Time of exposure to $5 \mathrm{mM}$ DESucc (mins)

Figure 1. Succinate causes carotid body (CB) chemoafferent stimulation. (a) Example CB chemoafferent recording of the response to 1,5, and $10 \mathrm{mM}$ diethyl succinate (DESucc). Raw voltage is shown (upper) along with frequency histograms (lower). Overdrawn action potentials are inset, demonstrating single fibre discrimination. (b) Mean steady-state responses to DESucc at 1,5 , and $10 \mathrm{mM}$ concentrations ( $n=9$ fibres, $N=4$ animals). Data presented as box-whisker plots with median, mean (shown as + ), the box representing the interquartile range and the whiskers extending to outliers. Single points represent individual fibres. ${ }^{* *}$ and ${ }^{* * *}$ denote $p<0.01$ and $p<0.001 \mathrm{vs.} 0 \mathrm{mM}$, one-way repeated measures ANOVA with Dunnett's post hoc test. (c) Time course of prolonged exposure to $5 \mathrm{mM}$ DESucc ( $n=11$ fibres, $N=5$ animals). Data presented as mean \pm SEM. ${ }^{*}$ and ${ }^{* *}$ denote $p<0.05$ and $p<0.01$ vs. 0 min, one-way repeated measures ANOVA with Dunnett's post hoc test. 
(a)
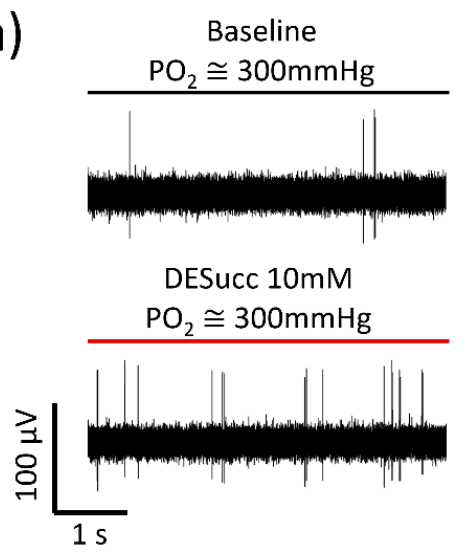

(c)

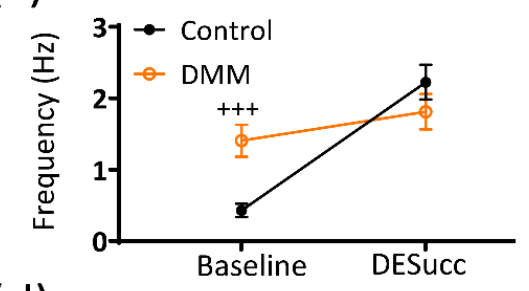

(d)

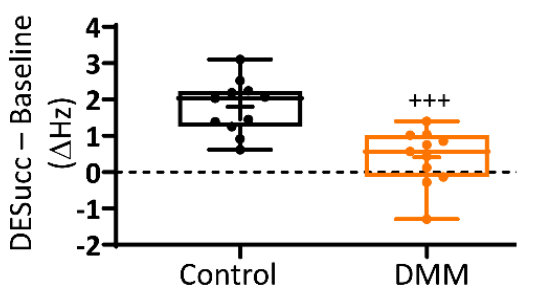

DESucc $5 \mathrm{mM}$

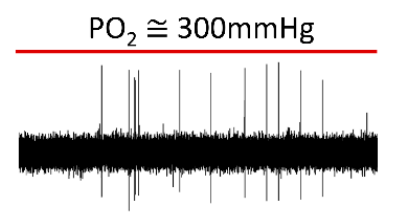

Peak hypoxia

$\mathrm{PO}_{2} \cong 60 \mathrm{mmHg}$

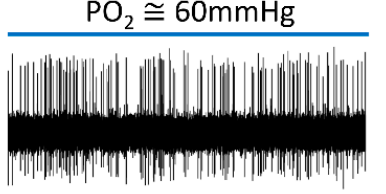

(b)

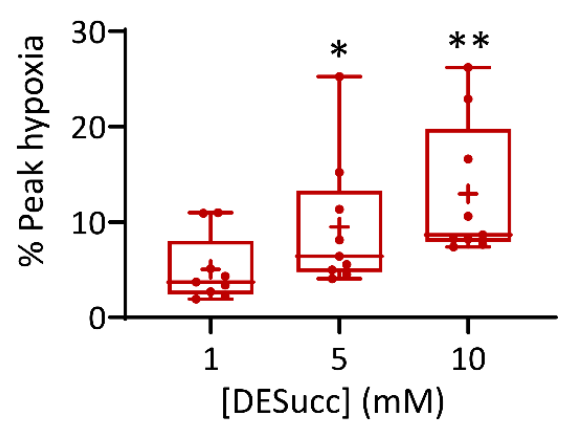

(g)

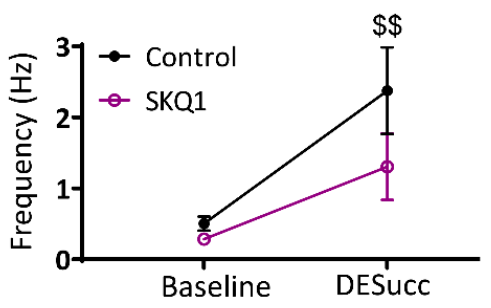

(h)

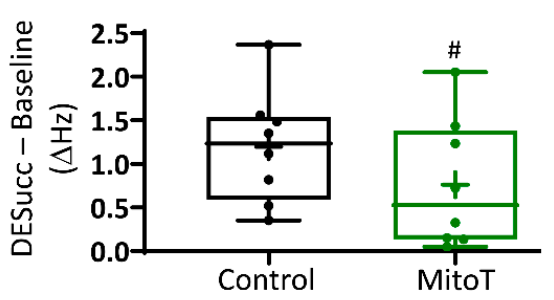

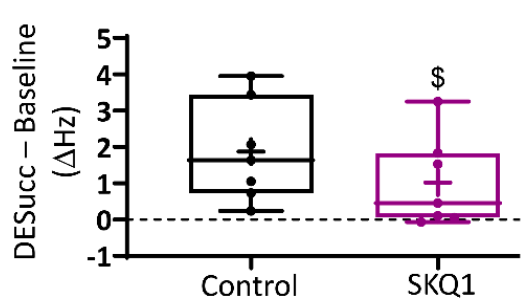

Figure 2. The carotid body $(\mathrm{CB})$ response to succinate is dependent on mitochondrial complex II activity and reactive oxygen species generation. (a) Example $5 \mathrm{~s}$ raw $\mathrm{CB}$ chemoafferent recordings from the same fibre comparing activity in the presence of diethyl succinate (DESucc -5 and $10 \mathrm{mM}$ ) with peak hypoxia. (b) Mean responses to 1, 5, and $10 \mathrm{mM}$ DESucc as a percentage of peak hypoxia ( $n=9$ fibres, $N=4$ animals). ${ }^{*}$ and ${ }^{* *}$ denote $p<0.05$ and $p<0.01$ vs. 1 mM, one-way repeated measures ANOVA with Dunnett's post hoc test. (c,d) Absolute and changes in frequency caused by 5 mM DESucc $\pm 10 \mathrm{mM}$ dimethyl malonate (DMM), respectively ( $n=11$ fibres, $N=5$ animals). (e,f) Absolute and changes in frequency caused by $5 \mathrm{mM}$ DESucc $\pm 20 \mu \mathrm{M}$ MitoTEMPO (MitoT), respectively ( $n=8$ fibres, $N=6$ animals). (g,h) Absolute and changes in frequency caused by $5 \mathrm{mM}$ DESucc $\pm 1 \mu \mathrm{M}$ SKQ1, respectively ( $n=6$ fibres, $N=5$ animals). For (c,e,g), data presented as mean \pm SEM. $+++p<0.001$ control vs. DMM, \# $p<0.05$ control vs. MitoT, $\$ \$ p<0.01$ control vs. SKQ1, two-way ANOVA with Tukey post hoc test. For $(\mathbf{d}, \mathbf{f}, \mathbf{h})$, data presented as box-whisker plots with median, mean (shown as + ), the box representing the interquartile range and the whiskers extending to outliers. Single points represent individual fibres. $+++p<0.001$ control vs. DMM, \# $p<0.05$ control vs. MitoT, $\$ p<0.05$ control vs. SKQ1, paired $t$-test.

\subsection{Excessive Succinate Metabolism Attenuates CB Hypoxic Sensitivity}

$\mathrm{CB}$ chemoafferent activity recorded during hypoxia exhibited a characteristic exponential increase below a certain $\mathrm{PO}_{2}$ threshold (Figure $3 \mathrm{a}, \mathrm{b}$ ). In the presence of $5 \mathrm{mM}$ DESucc, chemoafferent frequency in hypoxia was significantly decreased and the $\mathrm{PO}_{2}$ 'set-point' for hypoxic response initiation was left-shifted, suggestive of an attenuation of $\mathrm{O}_{2}$ sensitivity (Figure $3 \mathrm{a}-\mathrm{c}$ ). The inhibition of the hypoxic response caused by DESucc was reversible (Figure $3 \mathrm{a}, \mathrm{b})$. Application of a lower concentration of DESucc $(1 \mathrm{mM})$ did not alter the CB chemoafferent response to hypoxia (Figure 3d). 
(a)

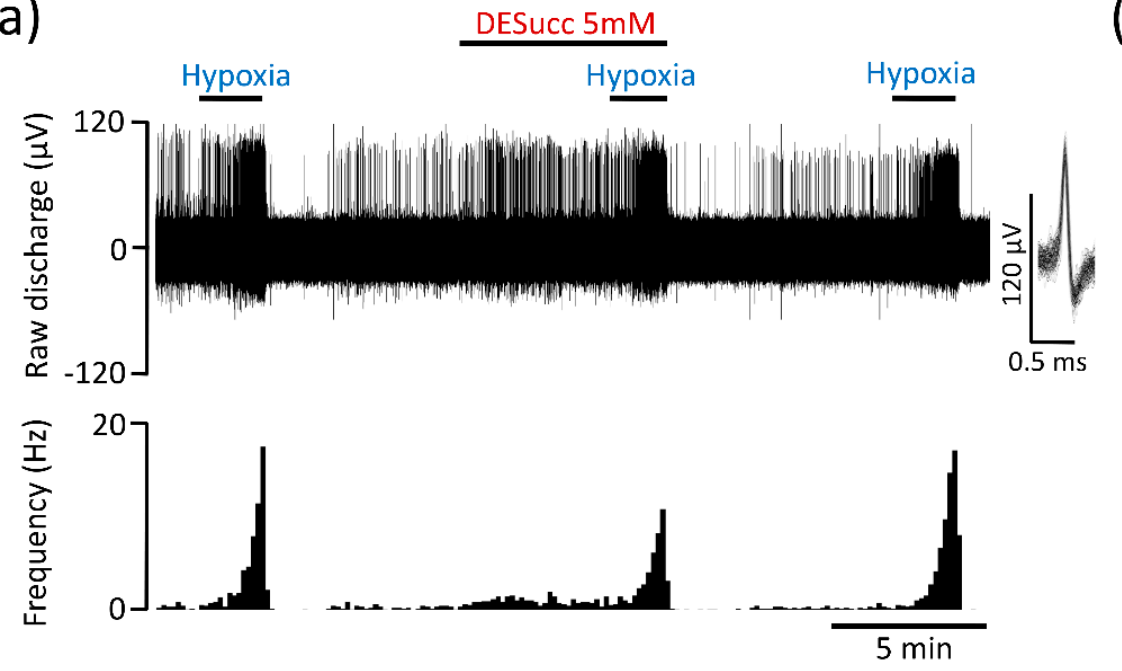

(b)

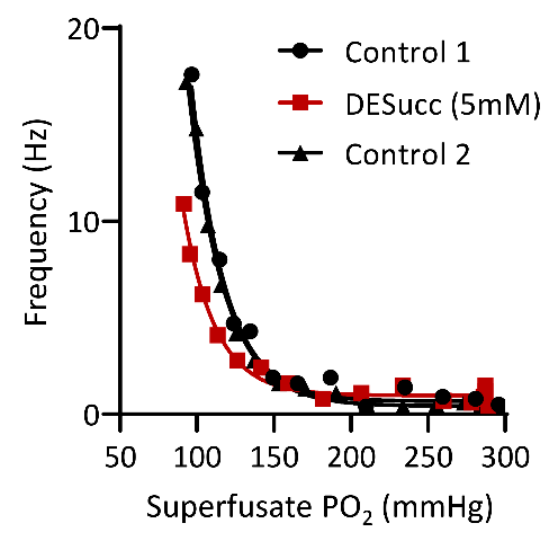

(d)

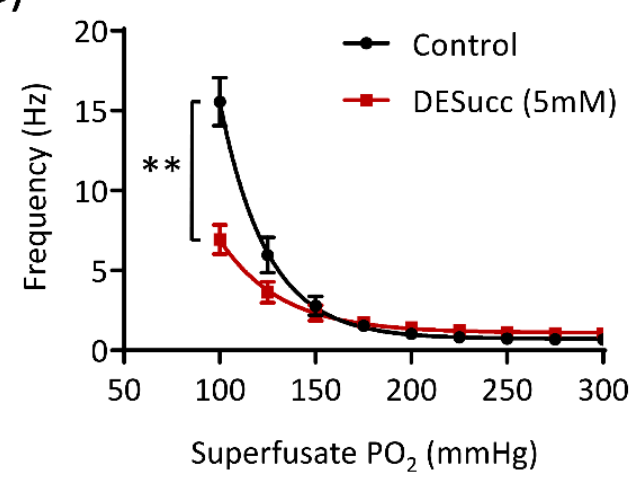

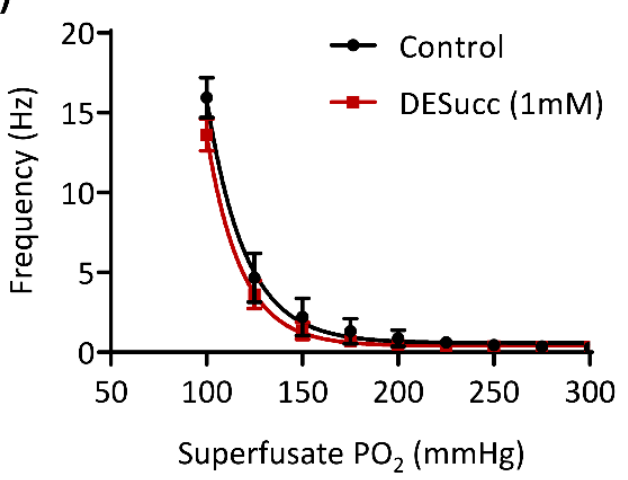

Figure 3. High levels of mitochondrial succinate metabolism depress carotid body hypoxic sensitivity. (a) Example CB chemoafferent recording of the response to hypoxia in the presence and absence of $5 \mathrm{mM}$ diethyl succinate (DESucc). Raw voltage is shown (upper) along with frequency histograms (lower). Inset: overdrawn action potentials. (b) $\mathrm{PO}_{2}-$ chemoafferent frequency response curves from a single experiment corresponding to the example shown in (a). (c) Mean chemoafferent hypoxic response curves for paired control and $5 \mathrm{mM} \mathrm{DESucc}$ ( $n=9$ fibres, $N=5$ animals). (d) Mean chemoafferent hypoxic response curves for paired control and $1 \mathrm{mM} \mathrm{DESucc}(n=5$ fibres, $N=5$ animals). Data presented as mean \pm SEM. ${ }^{* *}$ denotes $p<0.01$ vs. control, two-way repeated measures ANOVA.

\subsection{Mitochondrial Antioxidants and Inhibition of Succinate Metabolism Decrease but Do Not Abolish CB Chemoafferent Responses to Hypoxia}

To evaluate the importance of endogenous succinate metabolism, we monitored chemoafferent frequency in the presence of DMM $(10 \mathrm{mM}$; a cell permeable and competitive inhibitor of SDH, complex II). In normoxia, DMM caused rapid and reversible chemostimulation in all preparations tested (Figure $4 a, b$ ). The elevation above baseline was variable, lying within the range of $0.5-5.5 \mathrm{~Hz}$ and was maintained throughout the stimulus duration (Figure 4a,b). DMM also significantly decreased the chemoafferent frequency in hypoxia and evoked a left shift in the hypoxic response curve (Figure 4c-e). However, a significant component (greater than $50 \%$ ) of the overall hypoxic response was still preserved (Figure 4c-e). The inhibitory action of DMM on $\mathrm{CB} \mathrm{O}_{2}$ sensitivity was reversible as evidenced by restoration of the response to hypoxia after 10-15 min washout (Figure 4c,d). 
(a)

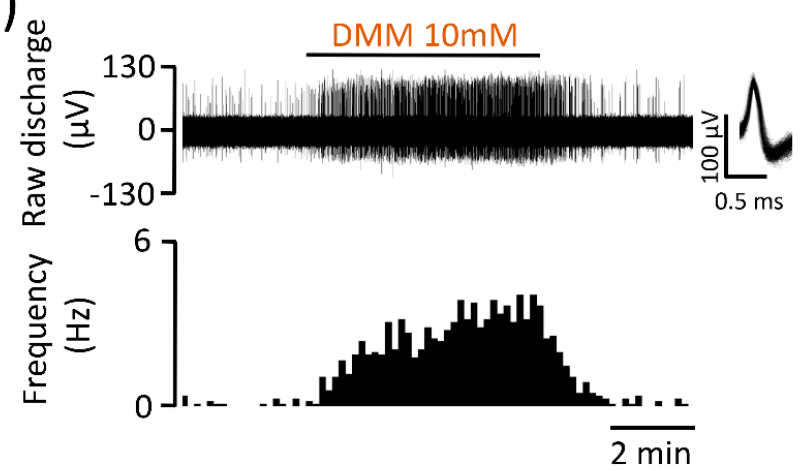

(b)

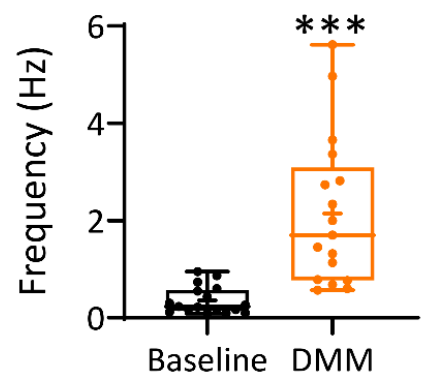

(c)

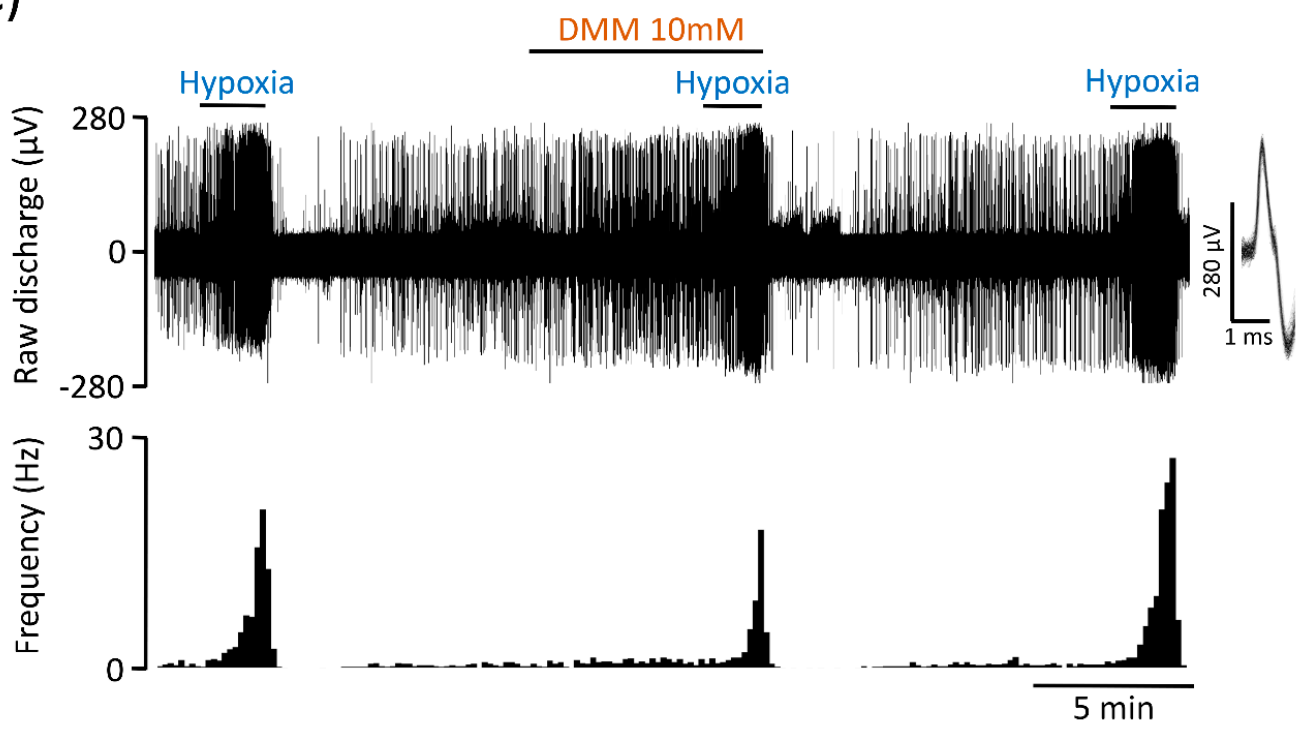

(d)

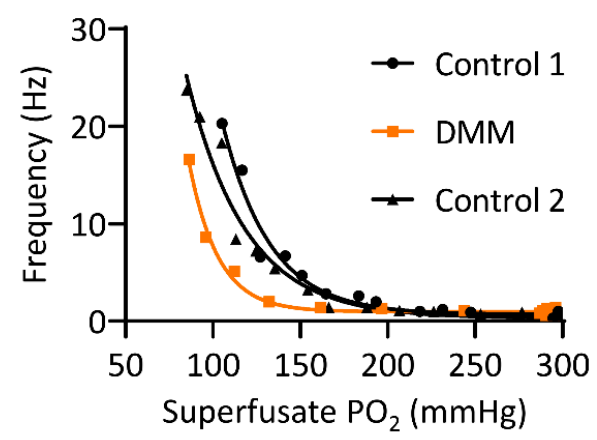

(e)

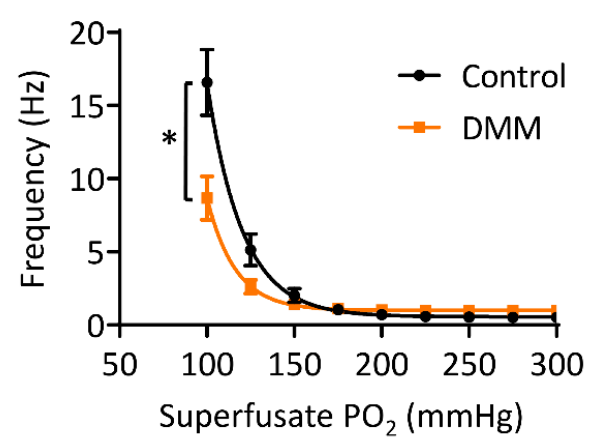

Figure 4. Inhibition of mitochondrial succinate metabolism causes basal carotid body $(\mathrm{CB})$ chemoafferent excitation but partially attenuates the response to hypoxia. (a) Example chemoafferent response to $10 \mathrm{mM}$ dimethyl malonate (DMM), an inhibitor of mitochondrial succinate dehydrogenase (complex II). Raw voltage (upper) is shown along with frequency histograms (lower). Inset: overdrawn action potentials. (b) Mean steady state frequency caused by DMM ( $n=17$ fibres, $N=10$ animals). Data presented as box-whisker plots with median, mean (shown as + ), the box representing the interquartile range and the whiskers extending to outliers. Single points represent individual fibres. ${ }^{* * *}$ denotes $p<0.001$ vs. baseline, paired $t$-test. (c) Example chemoafferent response to hypoxia in the presence and absence of $10 \mathrm{mM} \mathrm{DMM}$. (d) $\mathrm{PO}_{2}$-response curves from a single experiment corresponding to the example shown in (c). (e) Mean chemoafferent hypoxic response curves for paired control and $10 \mathrm{mM} \mathrm{DMM}$ ( $n=8$ fibres, $N=5$ animals). Data presented as mean \pm SEM. ${ }^{*}$ denotes $p<0.05$ vs. control, two-way repeated measures ANOVA. 
As succinate increases mitoROS generation as a by-product of respiration $[18,19,30]$, we assessed $\mathrm{CB}$ responses to hypoxia in presence of two different mitochondrial antioxidants MitoT $(20 \mu \mathrm{M})$ and SKQ1 $(1 \mu \mathrm{M})$. MitoT (which is targeted to the mitochondrial matrix) caused an attenuation in the rise in chemoafferent activity in hypoxia, without completely abolishing it, with a significant proportion of the response $(>50 \%)$ being preserved (Figure 5a-c). MitoT induced a left shift in the $\mathrm{PO}_{2}$ threshold for response initiation, suggestive of a decrease in $\mathrm{CB} \mathrm{O}_{2}$ sensitivity (Figure 5a-c). SKQ1, an antioxidant targeted to the mitochondrial intermembrane space, also decreased but did not fully eliminate the chemoafferent response to hypoxia (Figure $6 \mathrm{a}-\mathrm{c}$ ). At a superfusate $\mathrm{PO}_{2}$ of $100 \mathrm{mmHg}$, the response to hypoxia was blunted by approximately 20-50\% (Figure 6a-c). SKQ1 also produced a left shift in the $C B$ hypoxic response curve, signifying decreased $\mathrm{O}_{2}$ sensitivity (Figure $6 \mathrm{a}-\mathrm{c}$ ). Inhibition caused by MitoT and SKQ1 was not always reversible and there was a possibility that the decrease in $\mathrm{O}_{2}$ sensitivity was caused by a time dependent rundown during the 20-25 min incubation period. Additional experiments were performed comparing 2 control hypoxic responses $30 \mathrm{~min}$ apart. Paired chemoafferent responses for the same fibre separated by $30 \mathrm{~min}$ exhibited a high degree of consistency (Figure 6d), suggesting that the inhibition of $\mathrm{CB} \mathrm{O}_{2}$ sensitivity observed in the presence of MitoT and SKQ1 was not due to time-dependent preparation run-down.

\subsection{Mitochondrial Antioxidants Decrease Ventilatory Responses to Hypoxia but Not Hypercapnia}

Administration of a relatively low dose of MitoT $\left(1.96 \mu \mathrm{M} \mathrm{kg}^{-1}\right.$, I.P.) did not modify basal $R_{f}, V_{T}$, and $V_{E}$ or the ventilatory response to hypoxia and hypercapnia (Table 1). At a higher dose $\left(19.6 \mu \mathrm{M} \mathrm{kg}^{-1}\right.$, I.P.), MitoT had no effect on normoxic $R_{\mathrm{f}}$ but did decrease the rise in $R_{f}$ induced by hypoxia (Figure 7a-d, Table 1). The overall hypoxic ventilatory response (HVR) was unaffected, suggesting a partial compensation of increased $\mathrm{V}_{\mathrm{T}}$ (Figure 7e-g, Table 1). The $19.6 \mu \mathrm{M} \mathrm{kg}^{-1}$, I.P. dose of MitoT had no impact on any component of the hypercapnic ventilatory response (Table 1).

Table 1. Changes in respiratory variables $\left(\mathrm{R}_{\mathrm{f}}\right.$-respiratory frequency; $\mathrm{V}_{\mathrm{T}}$-tidal volume; $\mathrm{V}_{\mathrm{E}}$-minute ventilation) in response to hypoxia or hypercapnia in the presence or absence of saline, MitoTEMPO or SKQ1.

\begin{tabular}{|c|c|c|c|c|c|c|}
\hline Exposure & Intervention & & $\mathbf{N}$ & $\begin{array}{c}\Delta \mathrm{R}_{\mathrm{f}} \\
(\mathrm{bpm})\end{array}$ & $\begin{array}{c}\Delta V_{T} \\
\left(m L g^{-1}\right)\end{array}$ & 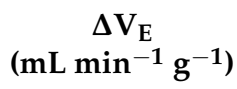 \\
\hline \multirow{8}{*}{$\begin{array}{l}\text { Hypoxia } \\
\left(10 \% \mathrm{O}_{2}\right)\end{array}$} & \multirow{2}{*}{ Vehicle control (saline) } & - & 5 & $42.2 \pm 7$ & $0.0012 \pm 0.0004$ & $0.39 \pm 0.06$ \\
\hline & & + & 5 & $43.7 \pm 6$ & $0.002 \pm 0.0003$ & $0.5 \pm 0.02$ \\
\hline & MitoTEMPO & - & 6 & $57.8 \pm 10.7$ & $0.0012 \pm 0.0002$ & $0.47 \pm 0.055$ \\
\hline & $\left(1.96 \mu \mathrm{M} \mathrm{kg}^{-1}\right)$ & + & 6 & $50.6 \pm 7.9$ & $0.0014 \pm 0.00025$ & $0.4 \pm 0.03$ \\
\hline & MitoTEMPO & - & 8 & $53 \pm 5.3$ & $0.001 \pm 0.0002$ & $0.53 \pm 0.07$ \\
\hline & $\left(19.6 \mu \mathrm{M} \mathrm{kg}^{-1}\right)$ & + & 8 & $41.6 \pm 7.2 *$ & $0.0015 \pm 0.0004$ & $0.44 \pm 0.027$ \\
\hline & SKQ1 & - & 6 & $52.8 \pm 6$ & $0.0014 \pm 0.00025$ & $0.5 \pm 0.03$ \\
\hline & $\left(500 \mathrm{nM} \mathrm{kg}^{-1}\right)$ & + & 6 & $37.7 \pm 5.7 *$ & $0.0016 \pm 0.0002$ & $0.4 \pm 0.03 *$ \\
\hline \multirow{8}{*}{$\begin{array}{l}\text { Hypercapnia } \\
\qquad\left(6 \% \mathrm{CO}_{2}\right)\end{array}$} & \multirow{2}{*}{ Vehicle control (saline) } & - & 5 & $81 \pm 7$ & $0.003 \pm 0.0006$ & $0.87 \pm 0.14$ \\
\hline & & + & 5 & $84.7 \pm 11$ & $0.003 \pm 0.0005$ & $0.86 \pm 0.12$ \\
\hline & MitoTEMPO & - & 6 & $87 \pm 8.5$ & $0.003 \pm 0.0003$ & $0.94 \pm 0.11$ \\
\hline & $\left(1.96 \mu \mathrm{M} \mathrm{kg}^{-1}\right)$ & + & 6 & $80.9 \pm 7.7$ & $0.0018 \pm 0.0002 *$ & $0.75 \pm 0.09$ \\
\hline & MitoTEMPO & - & 8 & $71.6 \pm 5.5$ & $0.003 \pm 0.00025$ & $0.98 \pm 0.07$ \\
\hline & $\left(19.6 \mu \mathrm{M} \mathrm{kg}^{-1}\right)$ & + & 8 & $66.7 \pm 3.8$ & $0.003 \pm 0.0002$ & $0.89 \pm 0.05$ \\
\hline & SKQ1 & - & 6 & $68.6 \pm 3.8$ & $0.0025 \pm 0.0005$ & $0.78 \pm 0.06$ \\
\hline & $\left(500 \mathrm{nM} \mathrm{kg}^{-1}\right)$ & + & 6 & $72.6 \pm 8$ & $0.003 \pm 0.0005$ & $0.82 \pm 0.07$ \\
\hline
\end{tabular}

${ }^{*} p<0.05$; paired $t$-test. Vehicle control— $n=5$; MitoTEMPO $\left(1.96 \mu \mathrm{M} \mathrm{kg}^{-1}\right)-n=6$; MitoTEMPO $\left(19.6 \mu \mathrm{M} \mathrm{kg}^{-1}\right)-n=8$; SKQ1(500 nM kg $\left.{ }^{-1}\right)-n=6$. 
(a)
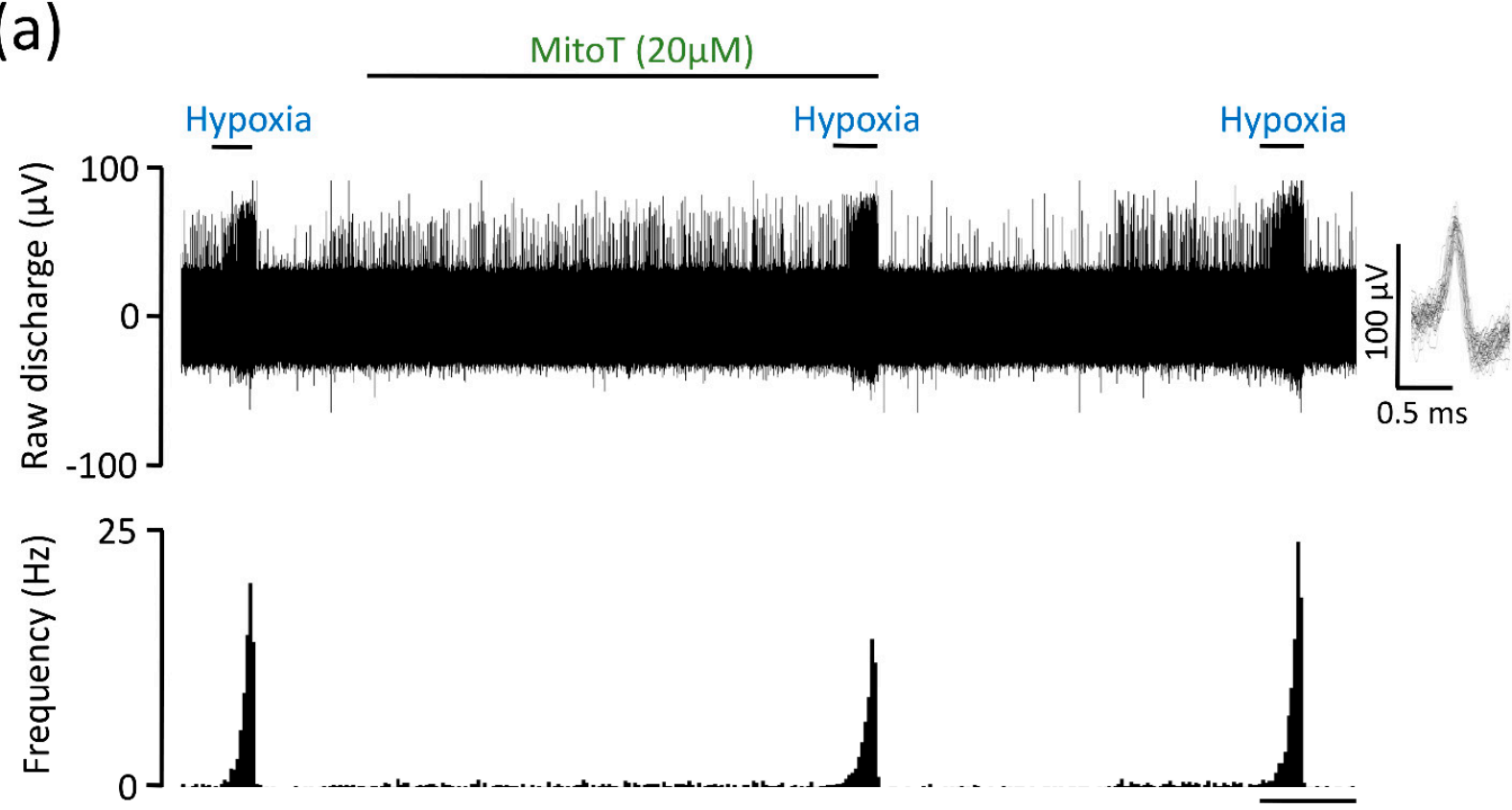

(b)

(c)
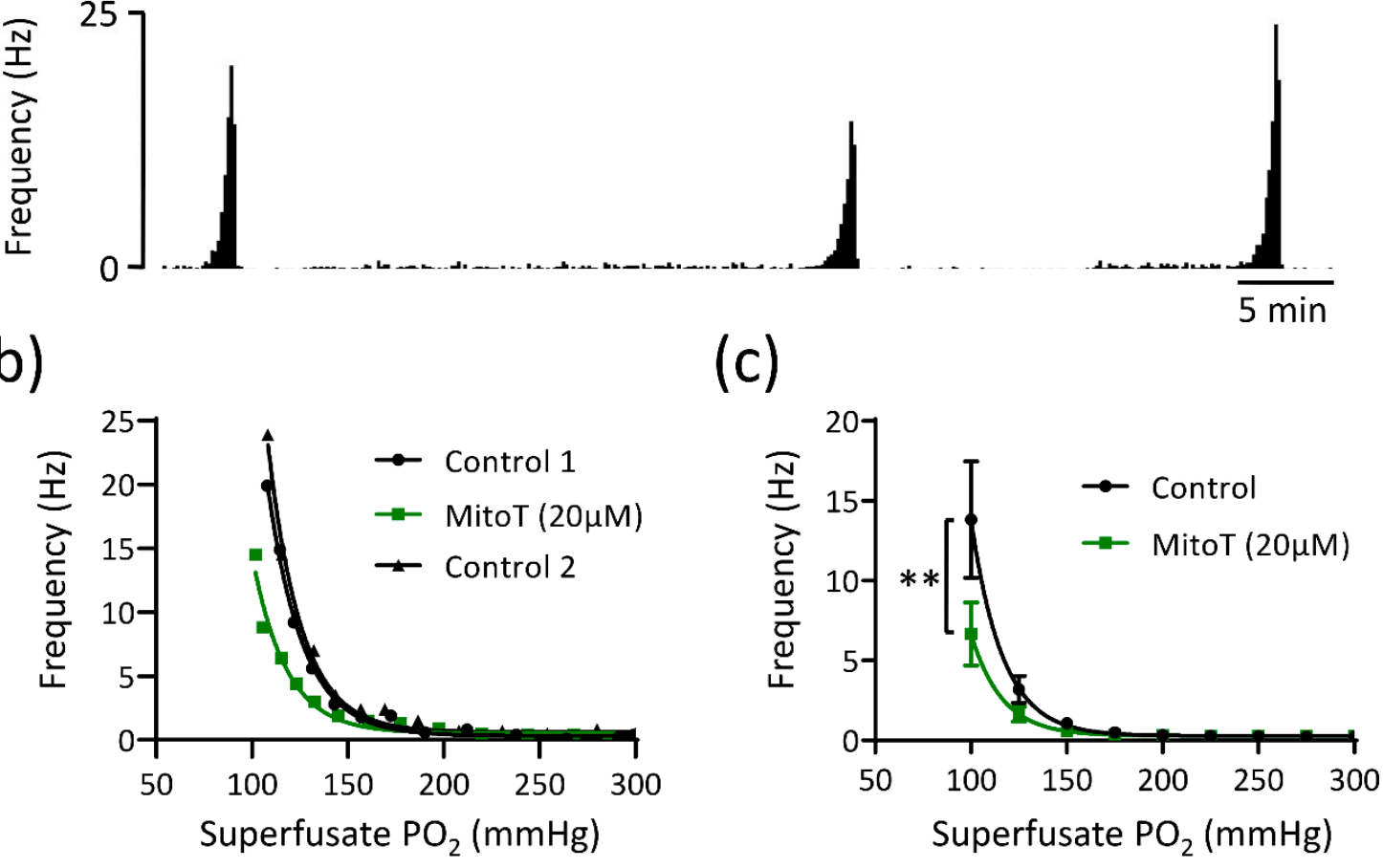

Figure 5. The mitochondrial antioxidant MitoTEMPO (MitoT) decreases but does not abolish carotid body (CB) chemoafferent responses to hypoxia. (a) Raw CB chemoafferent recording of the response to hypoxia $\pm 20 \mu \mathrm{M}$ MitoT. Raw voltage is shown (upper) along with frequency histograms (lower). Inset: overdrawn action potentials from a single fibre. (b) $\mathrm{PO}_{2}$-chemoafferent frequency response curves from a single experiment corresponding to the example shown in (a). (c) Mean chemoafferent hypoxic response curves for paired control and $20 \mu \mathrm{M}$ MitoT ( $n=9$ fibres, $N=6$ animals). Data are presented as mean \pm SEM. ${ }^{* *}$ denotes $p<0.01$ MitoT vs. control, two-way repeated measures ANOVA. 
(a)

SKQ1 $(1 \mu \mathrm{M})$

Hypoxia Hypoxia Hypoxia

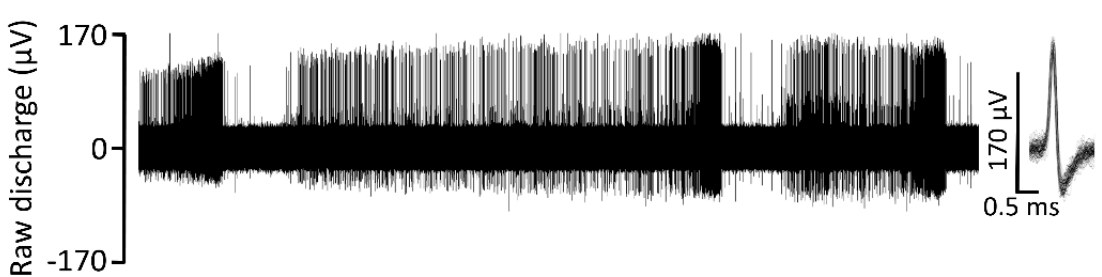

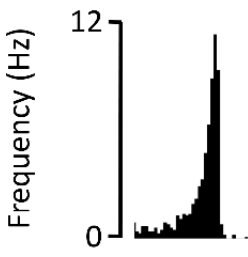

(c)

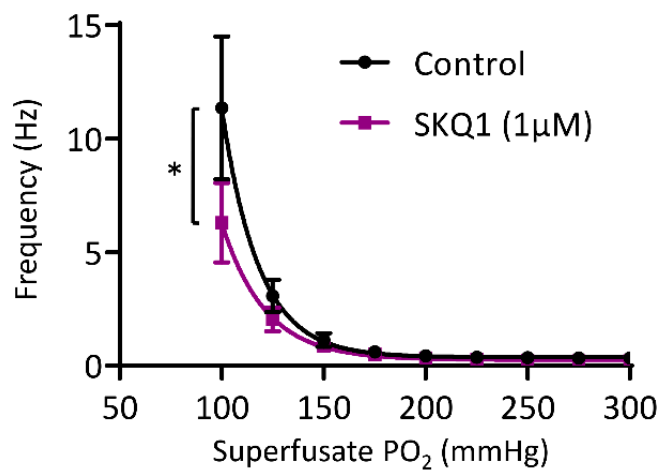

(b)

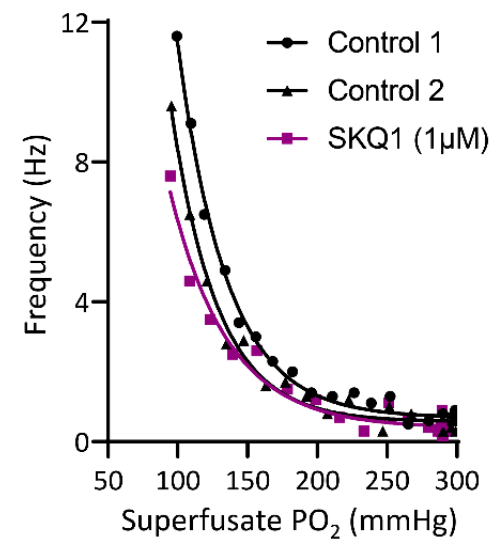

(d)

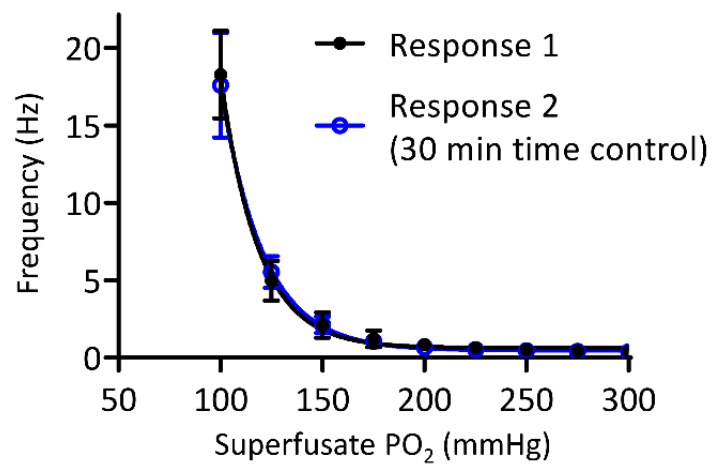

Figure 6. The mitochondrial antioxidant SKQ1 partially attenuates carotid body (CB) chemoafferent responses to hypoxia. (a) Raw CB chemoafferent recording of the response to hypoxia $\pm 1 \mu \mathrm{M}$ SKQ1. Raw voltage is shown (upper) along with frequency histograms (lower). Inset: overdrawn action potentials from a single fibre. (b) $\mathrm{PO}_{2}$-chemoafferent frequency response curves from a single experiment corresponding to the example shown in (a). (c) Mean chemoafferent hypoxic response curves for paired control and $1 \mu \mathrm{M}$ SKQ1 ( $n=9$ fibres, $N=6$ animals). (d) Mean chemoafferent hypoxic response curves for 2 repeated control hypoxic exposures separated by $30 \mathrm{~min}$ ( $n=7$ fibres, $N=7$ animals). For (c,d), data are presented as mean \pm SEM. * denotes $p<0.05$ SKQ1 vs. control, two-way repeated measures ANOVA. 
(a)

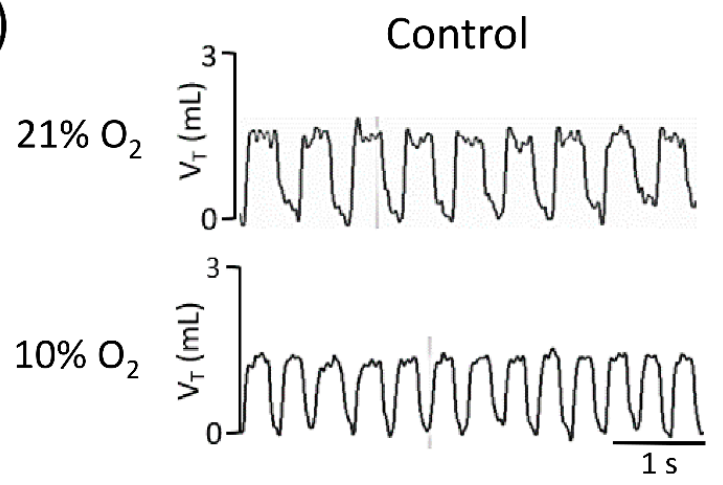

(b)

(e)
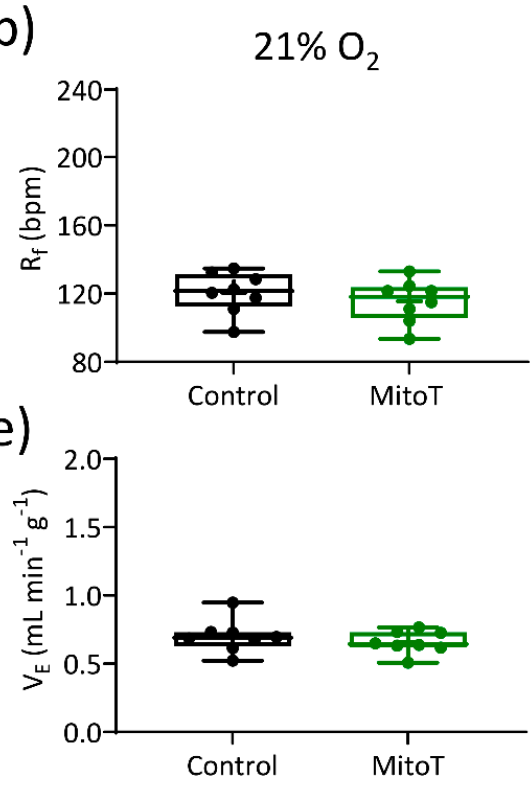

(c)

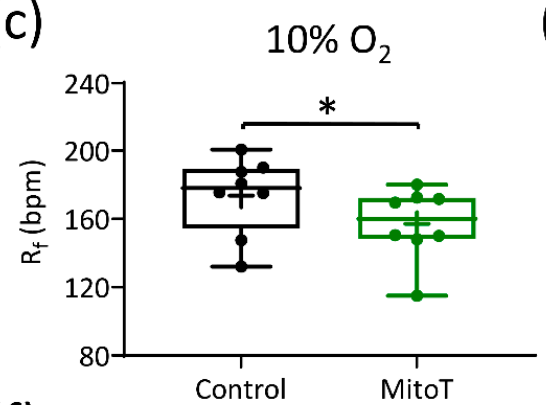

(f)

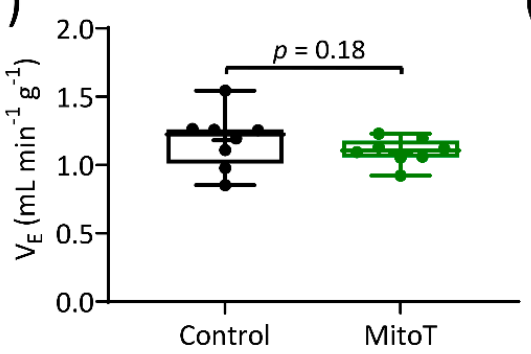

+MitoT
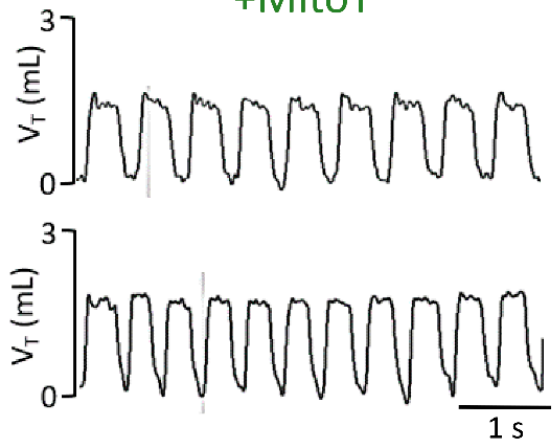

Figure 7. MitoTEMPO (MitoT) decreases the rise in respiratory frequency $\left(\mathrm{R}_{\mathrm{f}}\right)$ during hypoxia. (a) Representative respiratory traces (tidal volume $\left(\mathrm{V}_{\mathrm{T}}\right)$ vs. time, $5 \mathrm{~s}$ ) illustrating breathing pattern before (left) and after (right) MitoT administration $\left(19.6 \mu \mathrm{M} \mathrm{kg}^{-1}\right.$, I.P.), in normoxia $\left(21 \% \mathrm{O}_{2}\right)$ and during hypoxia $\left(10 \% \mathrm{O}_{2}\right)$. (b-d) Mean $\mathrm{R}_{\mathrm{f}}$ in normoxia, hypoxia and the relative change, respectively, before and after MitoT $\left(N=8\right.$ animals). (e-g) Mean minute ventilation ( $\left.V_{\mathrm{E}}\right)$ in normoxia, hypoxia and the relative change, before and after MitoT. Data presented in box and whisker plots show mean (+), median line with a box range of 25 th and 75 th percentiles and outlier whiskers at minimum and maximum. Single points represent individual animals. * denotes $p<0.05$, paired $t$-test.

Representative traces illustrating breathing pattern at baseline and in response to hypoxia in presence and absence of SKQ1 are presented in Figure 8a. Following SKQ1 administration (500 $\mathrm{nM} \mathrm{kg}^{-1}$, I.P.), the basal $R_{\mathrm{f}}$ was markedly decreased, as was the elevation in $R_{\mathrm{f}}$ caused by hypoxia (Figure $8 \mathrm{a}-\mathrm{d}$, Table 1 ). Although there was still a robust increase in $\mathrm{V}_{\mathrm{E}}$ during hypoxia, SKQ1 significantly attenuated the HVR by approximately $20 \%$ (Figure 8e-g). In contrast, SKQ1 had no effect on the response to hypercapnia (Table 1), suggesting that SKQ1 selectively inhibited hypoxic sensing within the whole animal. 
(a)

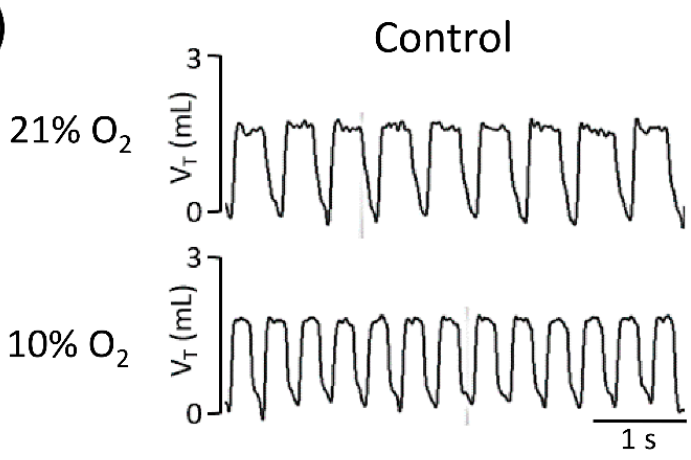

(b)
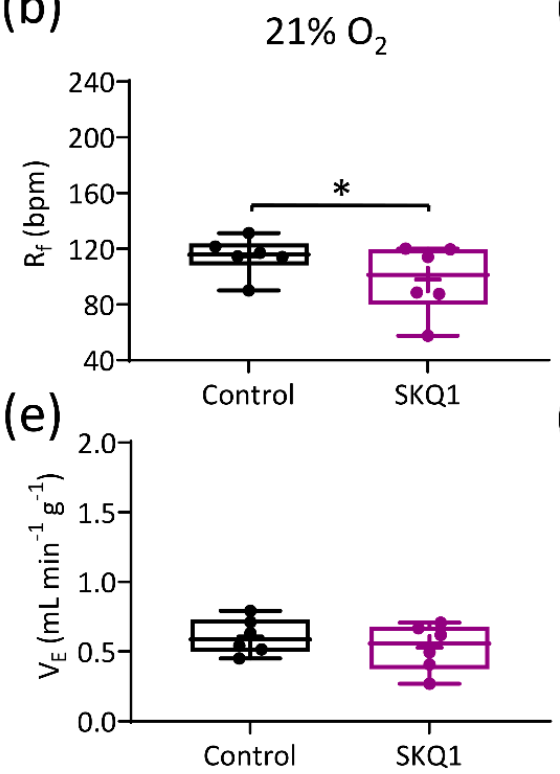
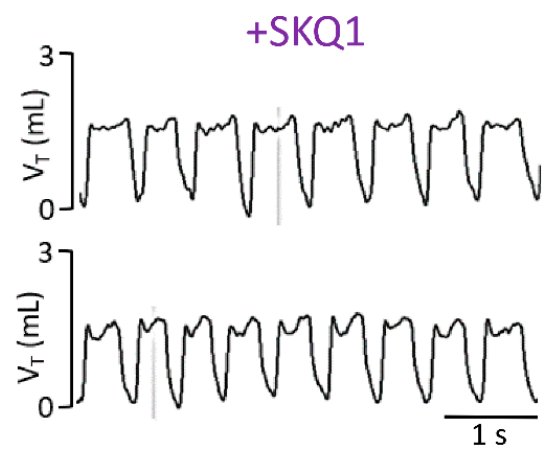

(c)

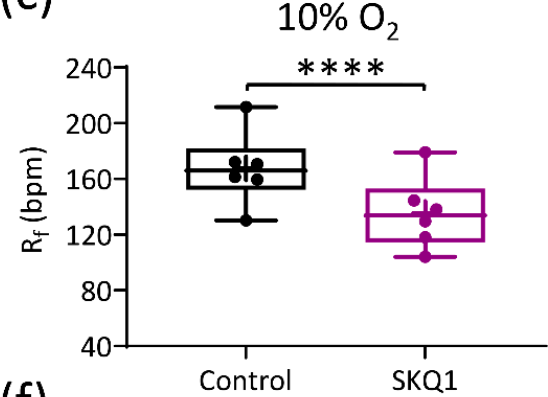

(f)

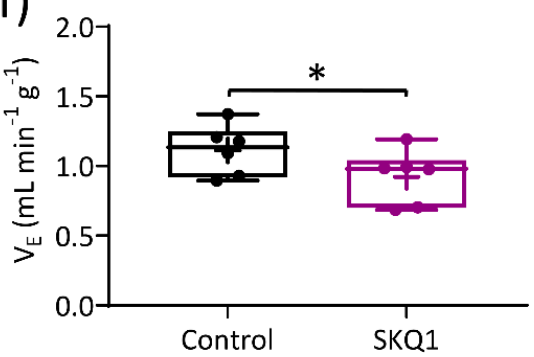

(d)

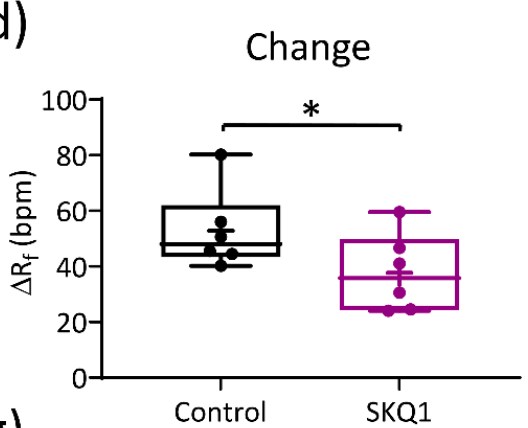

(g)

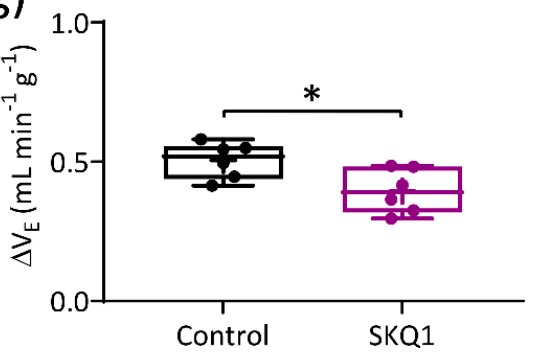

Figure 8. The mitochondrial antioxidant SKQ1 decreases the hypoxic ventilatory response (HVR). (a) Representative respiratory traces (tidal volume $\left(\mathrm{V}_{\mathrm{T}}\right)$ vs. time, $5 \mathrm{~s}$ ) illustrating breathing pattern before (left) and after (right) SKQ1 administration (500 $\mathrm{nM} \mathrm{kg}^{-1}$, I.P.), in normoxia $\left(21 \% \mathrm{O}_{2}\right)$ and during hypoxia $\left(10 \% \mathrm{O}_{2}\right)$. (b-d) Mean $\mathrm{R}_{\mathrm{f}}$ in normoxia, hypoxia, and the relative change, respectively, before and after SKQ1 ( $N=6$ animals). (e-g) Mean minute ventilation ( $\left.V_{E}\right)$ in normoxia, hypoxia, and the relative change (HVR), before and after SKQ1. Data presented in box and whisker plots show mean $(+)$, median line with a box range of 25th and 75th percentiles and outlier whiskers at minimum and maximum. Single points represent individual animals. ${ }^{*}$ and ${ }^{* * *}$ denote $p<0.05$ and $p<0.001$ control vs. SKQ1 respectively, paired $t$-test.

Time/vehicle control experiments were performed before and $1 \mathrm{~h}$ after I.P. injection with vehicle (saline) and demonstrated consistent breathing patterns and responses to hypoxia and hypercapnia (Table 1).

\section{Discussion \\ 4.1. Main Findings}

The present study shows that inhibition of succinate metabolism at mitochondrial complex II and mitochondrial antioxidants both partially attenuate the rat CB chemoafferent response to hypoxia. Mitochondrial antioxidants also decrease the rise in $\mathrm{R}_{\mathrm{f}}$ in hypoxia and, in the case of SKQ1, the HVR. However, at the level of the CB and in the whole animal, a significant component (50-80\%) of the response to hypoxia remains intact. Thus, whilst the data support a role for succinate metabolism and mitoROS being involved in CB and whole body $\mathrm{O}_{2}$ sensing, they are unlikely to be the sole mediators. Interestingly, excessive succinate metabolism causes modest chemoafferent stimulation in normoxia, but blunts activity in hypoxia. The additional inhibitory action of exaggerated succinate and mitoROS generation may have relevance in mediating CB dysfunction in disease. 


\subsection{Succinate and mitoROS Contribute to CB and Whole-Body Responses to Hypoxia in the Rat}

Numerous studies have implicated the $\mathrm{CB}$ mitochondria in acute $\mathrm{O}_{2}$ sensing in multiple species $[8,9,17,35]$. CB mitochondrial cytochrome c oxidase has an unusually high $\mathrm{K}_{\mathrm{m}}$ for $\mathrm{O}_{2}$ consistent with the $\mathrm{PO}_{2} \mathrm{~s}$ known to cause type I cell stimulation [9]. Emerging evidence indicates that the low $\mathrm{O}_{2}$ affinity of $\mathrm{CB}$ mitochondria could be due to a unique expression profile of mitochondrial electron transport chain complex subunits $[36,37]$ or the presence of a high level of a competitive inhibitor such as nitric oxide $[35,38]$.

There is now much focus on identifying the precise link between mitochondrial inhibition and activation of the downstream chemotransduction cascade: $\mathrm{K}^{+}$channel inhibition, membrane depolarisation, $\mathrm{Ca}^{2+}$ influx, neurotransmitter release, and chemoafferent excitation [35]. Our data identify an important role for succinate metabolism and mitoROS in mediating hypoxic sensitivity in the rat CB. Furthermore, we demonstrate that mitochondrial antioxidants and particularly SKQ1 can dampen the HVR in awake animals without impacting on hypercapnic ventilation. These findings are consistent with previous studies performed on isolated mouse type I cells where conditional deletion of mitochondrial complex I gene $n d u f s 2$ prevented hypoxia induced mitochondrial intermembrane ROS generation and rises in intracellular $\mathrm{Ca}^{2+}[17,18]$. Identifying a role for succinate and mitoROS in the intact $\mathrm{CB}$ preparation is an important finding as there are known differences between reduced and whole organ CB preparations in being able to sense and respond to other stimuli such as low glucose [39-42]. Furthermore, our data show that involvement of succinate and mitoROS in $\mathrm{CB} \mathrm{O}_{2}$ sensing is conserved between species and is present in the rat, albeit to a lesser extent. Validation of a similar role in the human $\mathrm{CB}$ is still warranted.

\subsection{Implications of the Current Study}

In the presence of DMM, MitoT, and SKQ1, although aspects of the ex vivo CB and in vivo ventilatory response to hypoxia were depressed, they were far from abolished, with around $50-80 \%$ being preserved. The stimulation with exogenous succinate led to an increase in the basal nerve discharge frequency, however it did not mimic hypoxia. Excitation by succinate was completely abolished by DMM and was attenuated by MitoT and SKQ1. This is consistent with succinate causing chemostimulation via metabolism at complex II, reverse electron transport (RET), and mitoROS generation. It was hypothesised that co-stimulation of the $\mathrm{CB}$ with succinate and hypoxia would potentiate the hypoxic response as reported by Arias-Mayenco and colleagues (2018) in isolated mice type I cells. On the contrary, our data show that such co-stimulation leads to a depression of hypoxic responsiveness in the ex vivo nerve preparation. Therefore, excessive succinate metabolism and mitoROS generation have additional inhibitory actions on CB function that may be relevant in pathophysiology or cellular plasticity e.g., ageing.

Our data support the idea that physiological levels of mitoROS are important in mediating some of the hypoxic chemotransduction, but not all. Changes in MgATP, lactate, and possibly other, as yet unidentified substances, may be necessary for a full response to hypoxia to be evoked $[13,15]$. The specific role of each mediator could be dependent on the specific intensity of hypoxia as has been suggested for release of neurotransmitters/neuromodulators [43]. That said, there are questions over a role of lactate being involved in $\mathrm{CB} \mathrm{O}_{2}$ sensing in the rat based on the recent finding that acute lactate administration (up to $20 \mathrm{mM}$ ) does not evoke type I cell depolarisation or chemoafferent excitation [44].

Alternatively, an upregulation of redundant control mechanisms in our experiments could account for the lack of complete abolition of the hypoxic response in the presence of DMM, MitoT, and SKQ1. The pharmacological approach used makes it difficult to separate out potential redundant control mechanisms, with those that are acting in parallel. If redundant mechanisms were at play in the current investigation, then they must have been induced very rapidly as pharmacological interventions were only applied for a maximum of $1 \mathrm{~h}$. The lack of complete elimination of the response to hypoxia in the presence of DMM, MitoT, and SKQ1 also does not rule out the involvement of other mediators independent 
of mitochondrial function including $\mathrm{H}_{2} \mathrm{~S}[45,46]$ and ROS derived from other sources such as NADPH oxidase $[47,48]$. Whilst mitoROS may be elevated in hypoxia, in other compartments, they may be decreased and the specific interactions between ROS and ion channels require further investigation. The importance of $\mathrm{H}_{2} \mathrm{~S}$ has also been challenged by the findings that mice lacking cystathionine- $\gamma$-lyase (CSE) have preserved CB and ventilatory responses to hypoxia [49]. Again, $\mathrm{O}_{2}$ stimulus intensity is likely to account for some of these apparent discrepancies, with $\mathrm{H}_{2} \mathrm{~S}$ generation now thought to be more relevant at moderate rather than severe hypoxic intensities [50]. Therefore, it is possible that there are many mediators, and their importance may be apparent at different severities of hypoxia, something that should be addressed in the future.

\subsection{Translational Relevance}

Lack of full understanding of the $\mathrm{CB}$ chemotransduction cascade undermines any attempts at designing potential treatment options for patients suffering from diseases associated with CB dysfunction, such as heart failure, hypertension, or obstructive sleep apnoea. One of the conclusions that can be drawn from the present study is that different levels of succinate metabolism, and consequently mitoROS, may have opposite effects on the $\mathrm{CB}$ activity and the response to hypoxia. The stimulatory impact of the succinate metabolism is likely to be important for initiation of the hypoxic response, whereas when very high excessive levels of succinate metabolism are reached, this may lead to detrimental accumulation of high levels of mitoROS. While ROS are known signalling molecules and are part of many signalling pathways, in severe excess, they cause damage to the cells and individual organelles, such as mitochondria. Providing that one of the hypotheses states that the oxygen sensor is located in the $\mathrm{CB}$ mitochondria, a major increase could have a detrimental impact on the overall oxygen sensing mechanism.

ROS have also been implicated in CB hyperactivity previously, although the focus so far has been on those derived from angiotensin II and NADPH oxidase [51-56]. Interestingly, it has been observed that mitochondrial superoxide dismutase nitration and protein expression is elevated in the $\mathrm{CB}$ following 7 days of chronic intermittent hypoxia $(\mathrm{CIH})$, suggestive of elevated mitoROS production [57]. Our data do identify that mitochondrial selective antioxidants are capable of dampening CB function, which could offer a new approach to reducing $\mathrm{CB}$ hyperactivity in certain pathologies. Evaluating mitoROS generation and mitochondrial function in the $\mathrm{CB}$ in multiple pathologies will be an important next step.

In the current investigation, DMM inhibition of mitochondrial complex II resulted in a pronounced chemoafferent excitation. We speculate that basal stimulation by DMM was a consequence of a slight fall in intracellular MgATP, but this requires validation in future work. Accordingly, previous studies identified persistent type I cell membrane depolarisation in mice lacking one $S D H D$ allele $\left(\mathrm{SDHD}^{+/-}\right)$[23]. These findings highlight a particularly high importance of succinate metabolism in maintaining normoxic electrical stability within the CB. Mutations in the SDHD gene are one of the causes of pheochromocytoma and paraganglioma, paragangliomas being the most prevalent type of CB cancer [58]. Whether or not the chronic stimulation itself contributes to oncogenesis (in addition to succinate dependent HIF1 $\alpha$ stabilisation) is an area that has not yet been fully explored, particularly in combination with ageing.

\subsection{Limitations}

A major part of this study was performed on ex vivo nerve preparation rather than isolated type I cells. While chemoafferent recordings are a validated way of assessing the hypoxic sensitivity, it is impossible to determine whether the effects of antioxidants and inhibitors used in this study are limited to type I cells. There could be potential effects on other cell types present in the $\mathrm{CB}$, such as type II cells or the nerve itself and therefore affect the final reading. Similar limitations apply to the in vivo studies as the antioxidants were administered systemically and they were not specifically targeted to the $\mathrm{CB}$ mitochondria. 
Therefore, some systemic effects on the cardiorespiratory system could have altered the response to hypoxia by disrupting ROS signalling. Finally, findings presented here were described in a rodent model, as such further studies are needed to determine whether the same effects are observed in humans.

\section{Conclusions}

Blocking succinate metabolism and the use of mitochondrial antioxidants decreases $\mathrm{O}_{2}$ sensing both at the level of the intact ex vivo $\mathrm{CB}$ and whole body HVR. However, significant proportions of the responses are preserved, suggesting that succinate-mediated mitoROS is not the only relevant signalling pathway. Excessive levels of succinate metabolism impair $\mathrm{CB}$ function in hypoxia. Treatment of the $\mathrm{CB}$ with mitochondrial selective antioxidants may offer a new approach for treating CB-related cardiovascular and respiratory disorders.

Author Contributions: Experimental concepts and method design were devised by A.S., A.M.C., N.B., C.J.R., P.K. and A.P.H. Data were collected by A.S., A.A.A., H.S.A. and A.P.H. Data were interpreted and analysed by A.S. and A.P.H. Original drafting of the manuscript was performed by A.S., P.K. and A.P.H. and was edited by all authors. Training and Supervision were provided to A.S. by A.A.A., H.S.A., A.M.C., N.B. and A.P.H. The project was administered by A.M.C. and A.P.H. Funding was acquired by A.A.A., H.S.A. and A.P.H. All authors have read and agreed to the published version of the manuscript.

Funding: "This work was funded by a Wellcome Trust Institutional Strategic Support Fund award to A.P.H., a Scholarship from Umm Al-Qura University (Makkah, Saudi Arabia) provided to A.A.A. through the Saudi Arabian Cultural Bureau in London and a Scholarship from King Saud bin Abdulaziz University for Health Sciences (Riyadh, Saudi Arabia) provided to H.S.A. through the Saudi Arabian Cultural Bureau in London." and "The APC was funded by University of Birmingham, UK."

Institutional Review Board Statement: All procedures were performed in accordance with UK Animals (Scientific Procedures) Act 1986 and approved by the UK Home Office (PPL number PF4C074AD) and by the Animal Welfare and Ethical Review Body (AWERB) at the University of Birmingham.

Informed Consent Statement: Not applicable.

Data Availability Statement: Throughout the manuscript, individual data points are presented and indicate averaged data from a single animal. Therefore, data generated or analysed during this study are included in this published article. The data presented in this study are available on request from the corresponding author.

Acknowledgments: The authors thank the staff members at the Biomedical Services Unit at University of Birmingham for their advice and technical assistance. The Graphical Abstract was created in BioRender.com.

Conflicts of Interest: The authors declare no conflict of interest.

\section{References}

1. Wiersinga, W.J.; Rhodes, A.; Cheng, A.C.; Peacock, S.J.; Prescott, H.C. Pathophysiology, Transmission, Diagnosis, and Treatment of Coronavirus Disease 2019 (COVID-19) A Review. JAMA J. Am. Med. Assoc. 2020, 324, 782-793. [CrossRef]

2. Ortega-Saenz, P.; Lopez-Barneo, J. Physiology of the Carotid Body: From Molecules to Disease. In Annual Review of Physiology; Nelson, M.T., Walsh, K., Eds.; Annual Review of Physiology; Annual Reviews: Palo Alto, CA, USA, 2020; Volume 82, pp. 127-149.

3. Kumar, P.; Prabhakar, N.R. Peripheral Chemoreceptors: Function and Plasticity of the Carotid Body. Compr. Physiol. 2012, 2, 141-219. [PubMed]

4. Prabhakar, N.R.; Semenza, G.L. Regulation of carotid body oxygen sensing by hypoxia-inducible factors. Pflug. Arch. 2016, 468, 71-75. [CrossRef] [PubMed]

5. Holmes, A.P.; Ray, C.J.; Thompson, E.L.; Alshehri, Z.; Coney, A.M.; Kumar, P. Adrenaline activation of the carotid body: Key to $\mathrm{CO} 2$ and $\mathrm{pH}$ homeostasis in hypoglycaemia and potential pathological implications in cardiovascular disease. Respir. Physiol. Neurobiol. 2019, 265, 92-99. [CrossRef]

6. Kumar, P. Systemic effects resulting from carotid body stimulation-invited article. Adv. Exp. Med. Biol. 2009, 648, $223-233$. [CrossRef] [PubMed] 
7. Rakoczy, R.J.; Wyatt, C.N. Acute oxygen sensing by the carotid body: A rattlebag of molecular mechanisms. J. Physiol. 2018, 596, 2969-2976. [CrossRef]

8. Duchen, M.R.; Biscoe, T.J. Mitochondrial function in type I cells isolated from rabbit arterial chemoreceptors. J. Physiol. 1992, 450, 13-31. [CrossRef] [PubMed]

9. Buckler, K.J.; Turner, P.J. Oxygen sensitivity of mitochondrial function in rat arterial chemoreceptor cells. J. Physiol. 2013, 591, 3549-3563. [CrossRef]

10. Mills, E.; Jobsis, F.F. Simultaneous measurement of cytochrome a3 reduction and chemoreceptor afferent activity in the carotid body. Nature 1970, 225, 1147-1149. [CrossRef]

11. Holmes, A.P.; Ray, C.J.; Coney, A.M.; Kumar, P. Is Carotid Body Physiological O2 Sensitivity Determined by a Unique Mitochondrial Phenotype? Front. Physiol. 2018, 9, 562. [CrossRef]

12. Chang, A.J. Acute oxygen sensing by the carotid body: From mitochondria to plasma membrane. J. Appl. Physiol. 2017, 123, 1335-1343. [CrossRef] [PubMed]

13. Chang, A.J.; Ortega, F.E.; Riegler, J.; Adison, D.V.M.; Krasnow, M.A. Oxygen regulation of breathing through an olfactory receptor activated by lactate. Nature 2015, 527, 240-244. [CrossRef] [PubMed]

14. Varas, R.; Buckler, K.J. Regulation of a TASK-like potassium channel in rat carotid body type I cells by ATP. Adv. Exp. Med. Biol. 2006, 580, 167-172. [CrossRef] [PubMed]

15. Varas, R.; Wyatt, C.N.; Buckler, K.J. Modulation of TASK-like background potassium channels in rat arterial chemoreceptor cells by intracellular ATP and other nucleotides. J. Physiol. 2007, 583, 521-536. [CrossRef] [PubMed]

16. Wyatt, C.N.; Evans, A.M. AMP-activated protein kinase and chemotransduction in the carotid body. Respir. Physiol. Neurobiol. 2007, 157, 22-29. [CrossRef] [PubMed]

17. Fernandez-Aguera, M.C.; Gao, L.; Gonzalez-Rodriguez, P.; Pintado, C.O.; Arias-Mayenco, I.; Garcia-Flores, P.; GarciaPerganeda, A.; Pascual, A.; Ortega-Saenz, P.; Lopez-Barneo, J. Oxygen Sensing by Arterial Chemoreceptors Depends on Mitochondrial Complex I Signaling. Cell Metab. 2015, 22, 825-837. [CrossRef]

18. Arias-Mayenco, I.; Gonzalez-Rodriguez, P.; Torres-Torrelo, H.; Gao, L.; Fernandez-Aguera, M.C.; Bonilla-Henao, V.; OrtegaSaenz, P.; Lopez-Barneo, J. Acute O2 Sensing: Role of Coenzyme QH2/Q Ratio and Mitochondrial ROS Compartmentalization. Cell Metab. 2018, 28, 145-158.e144. [CrossRef]

19. Chouchani, E.T.; Pell, V.R.; Gaude, E.; Aksentijevic, D.; Sundier, S.Y.; Robb, E.L.; Logan, A.; Nadtochiy, S.M.; Ord, E.N.J.; Smith, A.C.; et al. Ischaemic accumulation of succinate controls reperfusion injury through mitochondrial ROS. Nature 2014, 515, 431-435. [CrossRef]

20. McBryde, F.D.; Abdala, A.P.; Hendy, E.B.; Pijacka, W.; Marvar, P.; Moraes, D.J.; Sobotka, P.A.; Paton, J.F. The carotid body as a putative therapeutic target for the treatment of neurogenic hypertension. Nat. Commun. 2013, 4, 2395. [CrossRef]

21. Brognara, F.; Felippe, I.S.A.; Salgado, H.C.; Paton, J.F.R. Autonomic innervation of the carotid body as a determinant of its sensitivity: Implications for cardiovascular physiology and pathology. Cardiovasc. Res. 2021, 117, 1015-1032. [CrossRef]

22. Wyatt, C.N.; Buckler, K.J. The effect of mitochondrial inhibitors on membrane currents in isolated neonatal rat carotid body type I cells. J. Physiol. 2004, 556, 175-191. [CrossRef] [PubMed]

23. Piruat, J.I.; Pintado, C.O.; Ortega-Saenz, P.; Roche, M.; Lopez-Barneo, J. The mitochondrial SDHD gene is required for early embryogenesis, and its partial deficiency results in persistent carotid body glomus cell activation with full responsiveness to hypoxia. Mol. Cell Biol. 2004, 24, 10933-10940. [CrossRef] [PubMed]

24. Nunes, A.R.; Holmes, A.P.; Sample, V.; Kumar, P.; Cann, M.J.; Monteiro, E.C.; Zhang, J.; Gauda, E.B. Bicarbonate-sensitive soluble and transmembrane adenylyl cyclases in peripheral chemoreceptors. Respir. Physiol. Neurobiol. 2013, 188, 83-93. [CrossRef] [PubMed]

25. Holmes, A.P.; Turner, P.J.; Carter, P.; Leadbeater, W.; Ray, C.J.; Hauton, D.; Buckler, K.J.; Kumar, P. Glycogen metabolism protects against metabolic insult to preserve carotid body function during glucose deprivation. J. Physiol. 2014, 592, 4493-4506. [CrossRef] [PubMed]

26. Quintero, M.; Olea, E.; Conde, S.V.; Obeso, A.; Gallego-Martin, T.; Gonzalez, C.; Monserrat, J.M.; Gomez-Nino, A.; Yubero, S.; Agapito, T. Age protects from harmful effects produced by chronic intermittent hypoxia. J. Physiol. 2016, 594, 1773-1790. [CrossRef]

27. Sacramento, J.F.; Olea, E.; Ribeiro, M.J.; Prieto-Lloret, J.; Melo, B.F.; Gonzalez, C.; Martins, F.O.; Monteiro, E.C.; Conde, S.V. Contribution of adenosine and ATP to the carotid body chemosensory activity in ageing. J. Physiol. 2019, 597, 4991-5008. [CrossRef]

28. Holmes, A.P.; Nunes, A.R.; Cann, M.J.; Kumar, P. Ecto-5'-Nucleotidase, Adenosine and Transmembrane Adenylyl Cyclase Signalling Regulate Basal Carotid Body Chemoafferent Outflow and Establish the Sensitivity to Hypercapnia. In Arterial Chemoreceptors in Physiology and Pathophysiology; Peers, C., Kumar, P., Wyatt, C.N., Gauda, E., Nurse, C.A., Prabhakar, N., Eds.; Advances in Experimental Medicine and Biology; Springer: Berlin, Germany, 2015; Volume 860, pp. $279-289$.

29. Holmes, A.P.; Ray, C.J.; Pearson, S.A.; Coney, A.M.; Kumar, P. Ecto-5'-nucleotidase (CD73) regulates peripheral chemoreceptor activity and cardiorespiratory responses to hypoxia. J. Physiol. 2018, 596, 3137-3148. [CrossRef]

30. Mills, E.L.; Kelly, B.; Logan, A.; Costa, A.S.H.; Varma, M.; Bryant, C.E.; Tourlomousis, P.; Däbritz, J.H.M.; Gottlieb, E.; Latorre, I.; et al. Succinate Dehydrogenase Supports Metabolic Repurposing of Mitochondria to Drive Inflammatory Macrophages. Cell 2016, 167, 457-470.e413. [CrossRef] 
31. Dikalova, A.E.; Bikineyeva, A.T.; Budzyn, K.; Nazarewicz, R.R.; McCann, L.; Lewis, W.; Harrison, D.G.; Dikalov, S.I. Therapeutic Targeting of Mitochondrial Superoxide in Hypertension. Circ. Res. 2010, 107, 106-116. [CrossRef]

32. Antonenko, Y.N.; Avetisyan, A.V.; Bakeeva, L.E.; Chernyak, B.V.; Chertkov, V.A.; Domnina, L.V.; Ivanova, O.Y.; Izyumov, D.S.; Khailova, L.S.; Klishin, S.S.; et al. Mitochondria-targeted plastoquinone derivatives as tools to interrupt execution of the aging program. 1. Cationic plastoquinone derivatives: Synthesis and in vitro studies. Biochemistry 2008, 73, 1273-1287. [CrossRef]

33. Severin, F.F.; Severina, I.I.; Antonenko, Y.N.; Rokitskaya, T.I.; Cherepanov, D.A.; Mokhova, E.N.; Vyssokikh, M.Y.; Pustovidko, A.V.; Markova, O.V.; Yaguzhinsky, L.S.; et al. Penetrating cation/fatty acid anion pair as a mitochondria-targeted protonophore. Proc. Natl. Acad. Sci. USA 2010, 107, 663-668. [CrossRef] [PubMed]

34. Alzahrani, A.A.; Cao, L.L.; Aldossary, H.S.; Nathanael, D.; Fu, J.R.; Ray, C.J.; Brain, K.L.; Kumar, P.; Coney, A.M.; Holmes, A.P. beta-Adrenoceptor blockade prevents carotid body hyperactivity and elevated vascular sympathetic nerve density induced by chronic intermittent hypoxia. Pflug. Arch. 2021, 473, 37-51. [CrossRef] [PubMed]

35. Holmes, A.P.; Turner, P.J.; Buckler, K.J.; Kumar, P. Moderate inhibition of mitochondrial function augments carotid body hypoxic sensitivity. Pflug. Arch. 2016, 468, 143-155. [CrossRef]

36. Gao, L.; Bonilla-Henao, V.; Garcia-Flores, P.; Arias-Mayenco, I.; Ortega-Saenz, P.; Lopez-Barneo, J. Gene expression analyses reveal metabolic specifications in acute O-2-sensing chemoreceptor cells. J. Physiol. 2017, 595, 6091-6120. [CrossRef] [PubMed]

37. Moreno-Dominguez, A.; Ortega-Saenz, P.; Gao, L.; Colinas, O.; Garcia-Flores, P.; Bonilla-Henao, V.; Aragones, J.; Huttemann, M.; Grossman, L.I.; Weissmann, N.; et al. Acute O-2 sensing through HIF2 alpha-dependent expression of atypical cytochrome oxidase subunits in arterial chemoreceptors. Sci. Signal. 2020, 13, 13. [CrossRef] [PubMed]

38. Mosqueira, M.; Iturriaga, R. Carotid body chemosensory excitation induced by nitric oxide: Involvement of oxidative metabolism. Respir. Physiol. Neurobiol. 2002, 131, 175-187. [CrossRef]

39. Zhang, M.; Buttigieg, J.; Nurse, C.A. Neurotransmitter mechanisms mediating low-glucose signalling in cocultures and fresh tissue slices of rat carotid body. J. Physiol. 2007, 578, 735-750. [CrossRef]

40. Pardal, R.; Lopez-Barneo, J. Low glucose-sensing cells in the carotid body. Nat. Neurosci. 2002, 5, 197-198. [CrossRef]

41. Conde, S.V.; Obeso, A.; Gonzalez, C. Low glucose effects on rat carotid body chemoreceptor cells' secretory responses and action potential frequency in the carotid sinus nerve. J. Physiol. 2007, 585, 721-730. [CrossRef] [PubMed]

42. Gallego-Martin, T.; Fernandez-Martinez, S.; Rigual, R.; Obeso, A.; Gonzalez, C. Effects of low glucose on carotid body chemoreceptor cell activity studied in cultures of intact organs and in dissociated cells. Am. J. Physiol. Cell Physiol. 2012, 302, C1128-C1140. [CrossRef]

43. Conde, S.V.; Monteiro, E.C.; Rigual, R.; Obeso, A.; Gonzalez, C. Hypoxic intensity: A determinant for the contribution of ATP and adenosine to the genesis of carotid body chemosensory activity. J. Appl. Physiol. 2012, 112, 2002-2010. [CrossRef]

44. Spiller, P.F.; da Silva, M.P.; Moraes, D.J.A. Lactate does not activate the carotid body of Wistar rat. Respir. Physiol. Neuro. 2021, 285, 7. [CrossRef]

45. Peng, Y.J.; Nanduri, J.; Raghuraman, G.; Souvannakitti, D.; Gadalla, M.M.; Kumar, G.K.; Snyder, S.H.; Prabhakar, N.R. H2S mediates $\mathrm{O} 2$ sensing in the carotid body. Proc. Natl. Acad. Sci. USA 2010, 107, 10719-10724. [CrossRef] [PubMed]

46. Gallego-Martin, T.; Prieto-Lloret, J.; Aaronson, P.I.; Rocher, A.; Obeso, A. Hydroxycobalamin Reveals the Involvement of Hydrogen Sulfide in the Hypoxic Responses of Rat Carotid Body Chemoreceptor Cells. Antioxidants 2019, 8, 62. [CrossRef] [PubMed]

47. Bernardini, A.; Brockmeier, U.; Metzen, E.; Berchner-Pfannschmidt, U.; Harde, E.; Acker-Palmer, A.; Papkovsky, D.; Acker, H.; Fandrey, J. Type I cell ROS kinetics under hypoxia in the intact mouse carotid body ex vivo: A FRET-based study. Am J. Physiol. Cell Physiol. 2015, 308, C61-C67. [CrossRef] [PubMed]

48. Bernardini, A.; Wolf, A.; Brockmeier, U.; Riffkin, H.; Metzen, E.; Acker-Palmer, A.; Fandrey, J.; Acker, H. Carotid body type I cells engage flavoprotein and Pin1 for oxygen sensing. Am. J. Physiol. Cell Physiol. 2020, 318, C719-C731. [CrossRef]

49. Wang, J.J.; Hogan, J.O.; Wang, R.; White, C.; Kim, D. Role of cystathionine-gamma-lyase in hypoxia-induced changes in TASK activity, intracellular $\mathrm{Ca}^{2+}$ and ventilation in mice. Respir. Physiol. Neuro. 2017, 246, 98-106. [CrossRef]

50. Peng, Y.J.; Makarenko, V.V.; Gridina, A.; Chupikova, I.; Zhang, X.; Kumar, G.K.; Fox, A.P.; Prabhakar, N.R. H 2 S mediates carotid body response to hypoxia but not anoxia. Respir. Physiol. Neurobiol. 2019, 259, 75-85. [CrossRef]

51. Li, Y.L.; Gao, L.; Zucker, I.H.; Schultz, H.D. NADPH oxidase-derived superoxide anion mediates angiotensin II-enhanced carotid body chemoreceptor sensitivity in heart failure rabbits. Cardiovasc. Res. 2007, 75, 546-554. [CrossRef]

52. Marcus, N.J.; Li, Y.L.; Bird, C.E.; Schultz, H.D.; Morgan, B.J. Chronic intermittent hypoxia augments chemoreflex control of sympathetic activity: Role of the angiotensin II type 1 receptor. Respir. Physiol. Neurobiol. 2010, 171, 36-45. [CrossRef]

53. Roy, A.; Farnham, M.M.J.; Derakhshan, F.; Pilowsky, P.M.; Wilson, R.J.A. Acute intermittent hypoxia with concurrent hypercapnia evokes P2X and TRPV1 receptor-dependent sensory long-term facilitation in naive carotid bodies. J. Physiol. 2018, 596, 3149-3169. [CrossRef] [PubMed]

54. Peng, Y.J.; Nanduri, J.; Yuan, G.; Wang, N.; Deneris, E.; Pendyala, S.; Natarajan, V.; Kumar, G.K.; Prabhakar, N.R. NADPH oxidase is required for the sensory plasticity of the carotid body by chronic intermittent hypoxia. J. Neurosci. 2009, 29, 4903-4910. [CrossRef] [PubMed]

55. Yuan, G.; Peng, Y.-J.; Khan, S.A.; Nanduri, J.; Singh, A.; Vasavda, C.; Semenza, G.L.; Kumar, G.K.; Snyder, S.H.; Prabhakar, N.R. $\mathrm{H} 2 \mathrm{~S}$ production by reactive oxygen species in the carotid body triggers hypertension in a rodent model of sleep apnea. Sci. Signal. 2016, 9, ra80. [CrossRef] 
56. Aldossary, H.S.; Alzahrani, A.A.; Nathanael, D.; Alhuthail, E.A.; Ray, C.J.; Batis, N.; Kumar, P.; Coney, A.M.; Holmes, A.P. G-Protein-Coupled Receptor (GPCR) Signaling in the Carotid Body: Roles in Hypoxia and Cardiovascular and Respiratory Disease. Int. J. Mol. Sci. 2020, 21, 12. [CrossRef] [PubMed]

57. Moya, E.A.; Arias, P.; Iturriaga, R. Nitration of MnSOD in the Carotid Body and Adrenal Gland Induced by Chronic Intermittent Hypoxia. J. Histochem. Cytochem. 2018, 66, 753-765. [CrossRef] [PubMed]

58. Kluckova, K.; Tennant, D.A. Metabolic implications of hypoxia and pseudohypoxia in pheochromocytoma and paraganglioma. Cell Tissue Res. 2018, 372, 367-378. [CrossRef] 